\title{
At the End of the Day, Are Screens Good or Bad for You? A Critical Review of Randomized Controlled Studies
}

\begin{abstract}
In recent years, screen-based technologies have changed the way we communicate, study and consume goods, entertainment and information. Thus, our environment has changed profoundly, and it is reasonable to assume that children today have a different developmental environment compared to the past, making it crucial to understand the impact of our technology-rich environment on development as well as on physical and psychological wellbeing. The goal of the present paper is to provide a comprehensive review of randomized controlled studies assessing effects of screen use on physiology and behavior, in order to give as wide as possible a picture of screen use and its various effects. We conclude with a discussion focusing on the ability to reach "bottom lines" regarding the down- and upsides of screen-use. We also highlight and discuss the major areas in which knowledge about the effects of screens is lacking, requiring further high-quality and well-controlled studies.
\end{abstract}

Key words: screen-based technologies; development; psychological well-being; physical well-being; randomized controlled studies 


\section{Introduction}

The appearance of mobile devices and the growing use of the internet have influenced human society drastically and screen-based technologies have infiltrated all areas of life. The average American adult spends about 38 hours per week watching television (Boulos, Vikre, Oppenheimer, Chang, \& Kanarek, 2012) and in the USA people consume about seven hours of total screen-time a day (AdReaction Marketing in a multiscreen world Global Report, 2014). Media use is also very popular among children even at young ages, the age of first use is decreasing and hours of screen time are increasing (Bucksch et al., 2016; Hofferth \& Moon, 2012; Houghton et al., 2015). In 2003, American children spent about 17 hours per week using screen-based technologies (Hofferth, 2010). A study which surveyed 348 families showed that at the age of four, $50 \%$ of the surveyed children had their own TV and nearly $75 \%$ had their own mobile device. Nearly $50 \%$ of the children under 1 year and about $77 \%$ of the children under 2 years were using mobile device daily. On average, children in the study spent 109 minutes per day in front of screens with screen time increasing from an average of 78 minutes per day at one year of age to 140 minutes at the age of four (Kabali et al., 2015). A survey conducted in 2014 by the office of communications in the UK showed that $46 \%$ of three to four-year-olds and $94 \%$ of 12-15-year-olds own a media device. The survey also found that three to four-year-olds consume about 35 hours of media weekly, and this rises to about 51 hours at 12-15 years of age (Children and Parents: Media Use and Attitudes Report, 2014).

We know today that brain development continues roughly until the age of 21 (Giedd et al., 2015; Raznahan, Greenstein, Lee, Clasen, \& Giedd, 2012). During these formative years, the stimuli we are exposed to, both external (e.g. sights, sounds, physical sensations, social interactions etc.) and internal (e.g. feelings, thoughts, memories) will shape our brains, thus shaping our personality, reactions and behaviors (Dawson, Ashman, \& Carver, 2000; Fox, Levitt, \& Nelson, 2010; McEwen, 2012). Moreover, environmental changes can also lead to 
changes at the genetic level through epigenetic mechanisms, and these will also influence development (Bale, 2015; Roth \& Sweatt, 2011). An optimal milieu of stimuli encountered during development will favor a healthy developmental trajectory, leading to resilience and well-being. However, exposure to a non-optimal environment might lead to physical and psychological hardships and in extreme cases, to psychopathologies (Ellis, Boyce, Belsky, Bakermans-Kranenburg, \& Van Ijzendoorn, 2011; Johnson \& Wolke, 2013). The emphasis on an optimal developmental environment is especially important in young children and adolescents, because at these ages the brain is especially malleable and reactive to its environment. Large-scale neural changes take place, making these ages sensitive periods of brain development (Crews, He, \& Hodge, 2007; Hensch \& Bilimoria, 2012; Somerville, Jones, \& Casey, 2010).

Screen-based technologies have changed our environment in many ways. They have changed the kinds of sensory stimulation we are exposed to, the nature of our social interactions, and have been linked to changes in the amount of physical activity we engage in during the day (Sigmund et al., 2015; Tandon et al., 2014) and to our sleep duration and quality (Carter, Rees, Hale, Bhattacharjee, \& Paradkar, 2016; Hysing et al., 2015; Twenge, Krizan, \& Hisler, 2017). Thus, children growing up today have a different developmental environment compared to children in the past, making it crucial to understand the impact of a technologyrich environment on development. Apart from understanding the influences of cumulative screen-time it is also important to ask how specific types of screen-based content influence us. As Bavelier et al. (Bavelier, Green, \& Dye, 2010) state, it is simplistic to define screen-based technologies as "good" or "bad". Different content types have different influences, and some types of content have been shown to have both good and bad outcomes. Most studies of the effects of screen-based technologies focus on traditional mediums such as TV and computer games, due to the fact that smart mobile devices are still a relatively new technology. These 
studies report both negative and positive effects of screen-based technologies in domains such as cognition, aggression, mood, social behavior, nutrition and physical fitness. For example, although the common belief that extensive use of videogames may cause ADHD is currently not supported by the scientific evidence, playing videogames has been linked to more severe symptoms of ADHD in children and adolescents which are already diagnosed with ADHD (Chan \& Rabinowitz, 2006; Gentile, Swing, Lim, \& Khoo, 2012). On the other hand, it has also been linked to enhanced perceptual skills, improved attentional abilities, better working memory and enhanced executive functions (Reviewed in Bavelier, Green, Pouget, \& Schrater, 2012; Blumberg, Altschuler, Almonte, \& Mileaf, 2013; Boyle et al., 2016; Green \& Bavelier, 2012; Green \& Seitz, 2015). Regarding aggression and social behavior, exposure to violent videogames or violent $\mathrm{TV}$ has been linked to increased aggression and decreased pro-social behavior (Reviewed in C. A. Anderson et al., 2010; Brockmyer, 2015; Greitemeyer \& Mügge, 2014). On the other hand, exposure to pro-social videogames can enhance pro-social behaviors (Gentile et al., 2009; Greitemeyer \& Mügge, 2014; Greitemeyer \& Osswald, 2010). For physical fitness results are also mixed. Some studies link longer screen hours to an increased risk of being overweight and to poorer eating habits (Reviewed in Caroli, Argentieri, Cardone, \& Masi, 2004; LeBlanc et al., 2015; F. Li et al., 2015; Tsitsika et al., 2016). However, the same screen-based technologies, when used to encourage physical activity, have been found to contribute to weight loss and physical fitness (Reviewed in Bleakley et al., 2013; Peng, Crouse, \& Lin, 2012).

Despite their abundance, most studies focusing on the effects of screen-based technologies on physiology and behavior are correlational, making it hard to understand the causal relationship between screen exposure and physical and psychological functioning. The goal of the present paper is to provide a comprehensive review of randomized controlled studies assessing the effects of screen use. We chose not to target one medium (e.g. TV, 
videogames), content type (e.g. violent games, TV advertisements) or domain (e.g. aggressive behaviors, obesity), but to give a wide as possible a picture of screen use influences. Our goal is to understand if, at the end of the day, the cumulative use of screen-based technologies is beneficial or harmful. After reviewing the studies, we offer a critical discussion focusing on the ability to reach concrete conclusions regarding the downsides and benefits of screen-use. We also present the major areas in which knowledge about the influences of screens is lacking, thus requiring high-quality and well-controlled studies.

\section{Method}

\section{Search Method.}

The Pubmed database was searched using the query detailed in online appendix A. Then, the "snowball" method (Greenhalgh \& Peacock, 2005) was used and the reference list of all the studies located through Pubmed was manually searched for additional relevant studies.

\section{Exclusion Criteria.}

The following studies were excluded: studies that were not in English, studies that used screens to elicit responses in participants (e.g. exposure to movies for inducing emotions in laboratory settings), studies using screens for data collection and studies of screen-based clinical or educational interventions, as these do not relate to day-to day screen use. Also excluded were studies of electromagnetic fields emitted by screens, as this topic is out of the scope of this review.

\section{Results}

We located 150 randomized controlled studies in English published between 19632017. Studies are divided to those showing negative influences of screen exposure (including a null effect when a positive influence was expected) and those showing positive influences (including a null effect when a negative influence was expected). Then, studies are further 
subdivided by media type (TV, videogames, mobile devices, virtual reality), subjects' age (children/teenagers, adults) and domain (aggression/pro-social behavior, stereotypes/body image, cognitive abilities, physical fitness and nutrition, mood). Studies are summarized in table one (negative effects) and table two (positive effects). Due to the quantity of reviewed studies, experimental procedures are not described in detail and results are summarized to "bottom lines".

\section{Negative Effects of Screen Exposure}

\section{TV.}

Effects on aggression. We found nine studies assessing the effects of TV on aggression, five conducted with children, and four with adults.

Studies of TV and aggression in children. Bandura et al. (Bandura, Ross, \& Ross, 1963), Hicks (1965) and Liebert and Baron (1972) exposed children to violent TV content and showed that aggressive behaviors towards toys or other people increased compared to a passive control group (Bandura et al., 1963; Hicks, 1965) or a group watching non-violent TV content (Liebert \& Baron, 1972). Steuer et al. (1971) found similar results after 11 days of exposure to violent TV, compared to exposure to non-violent TV. Kohn Friedrich and Huston Stein (1973) exposed children to violent, neutral or pro-social TV for four weeks and found higher rates of interpersonal aggression, less tolerance for delay and less rule obedience after exposure to violent TV. Notably, watching pro-social TV content increased task-persistence, rule obedience, tolerance of delay and pro-social behavior.

Studies of TV and aggression in adults. Studies by Bushman and Geen (1990), Bushman (1998) and Anderson (1997) exposed participants to either violent or non-violent TV content. Bushman and Geen (1990) and Bushman (1998) showed that aggressive thoughts increased after exposure to TV violence. In addition, violent content increased self-reported hostility and blood pressure (Bushman \& Geen, 1990). Anderson (1997) showed that watching 
a violent movie clip led to higher state hostility. Scharrer (2005) found that men with aggressive tendencies showed increased state aggressiveness following exposure to violent content.

Effects on stereotypes. We were able to locate four randomized controlled studies testing the effects of TV on stereotypes regarding race or gender, all conducted with adults. Mastro et al. (Mastro, Behm-Morawitz, \& Kopacz, 2008) showed Caucasian participants stereotyped or stereotypically ambiguous TV clips. Participants adhered more to stereotypes in the ambiguous conditions and their self-esteem increased. In another study, Caucasian participants were exposed to a stereotypical or a non-stereotypical crime news report. Subjects allocated more guilt and responsibility to an African American suspect compared to a Caucasian suspect (Mastro, Lapinski, Kopacz, \& Behm-Morawitz, 2009). Milburn et al. (Milburn, Mather, \& Conrad, 2000) showed participants a movie sexually objectifying women or a control movie. After exposure to the sexual movie, male participants presented with a rape story thought that the victim enjoyed what happened to her. Ferguson et al. (T. Ferguson et al., 2005) showed participants clips depicting either promiscuous or non-promiscuous women. Those exposed to the promiscuous depiction judged a woman in a story about sexual harassment as less traumatized by the event and more responsible for what happened to her.

Effects on cognitive abilities. We located one randomized controlled study testing the effects of TV on cognitive abilities in adults. Bushman and Bonacci (2002) tested subjects' memory for TV ads embedded in either a violent, a sexual or a neutral TV program. Participants exposed to violent or sexual content remembered less ads than those who watched the neutral program.

Effects on physical fitness and nutrition. We located two randomized controlled studies testing the effects of TV on nutrition. In the first study (Harris, Bargh, \& Brownell, 2009) both children and adults ate more after watching TV with embedded snack food ads relative to controls who were exposed to non-food ads or to healthy food ads. In the second 
study (Higgs \& Woodward, 2009), women ate lunch while watching TV or while doing nothing. Eating lunch while watching TV led to an increase in snack intake and a decrease in memory for the lunch later in the day.

\section{Videogames.}

Effects on aggression/pro-social behavior. We located 43 studies testing videogames and aggression, seven carried out with children or adolescents and 36 with adults.

Studies of videogames and aggression in children. Cooper and Mackie (1986), Schutte et al. (1988) and Polman et al. (Polman, De Castro, \& Van Aken, 2008) had children play or watch a child play a violent or a non-violent videogame and tested the effects on aggressive play. In the first study exposure to the violent videogame increased aggressive play in girls, in the second, children who played the violent videogame had more aggressive play, and in the third only boys who played the violent videogame displayed more aggressive play. Irwin and Gross (1995) assigned children to play a violent or a non-violent videogame. Exposure to the violent videogame increased aggressive play and interpersonal aggression. Chambers and Ascione (1987) had children and adolescents play either a violent or a pro-social videogame, alone or in pairs. A no-game passive control group was also included. Results showed that in both conditions of the violent videogame play (i.e. alone or in pairs), participants exhibited less pro-social behaviors compared to the other conditions. Kirsh (1998) assigned children to play a violent or a non-violent videogame and then presented them with ambiguous stories. Participants exposed to the violent videogame responded more negatively to some of the questions regarding the ambiguous stories compared to controls. Konijn et al. (Konijn, Bijvank, \& Bushman, 2007) asked boys with low-academic ability to play a violent or a non-violent videogame. The boys who played the violent videogame were more aggressive as measured by a white noise paradigm in which their willingness to punish someone with loud bursts of white noise for making a mistake in a task was tested. 
Studies of videogames and aggression in adults. Apart from two studies which tested long-term effects (Bushman \& Gibson, 2011; Teng, Chong, Siew, \& Skoric, 2011), all others tested short-term exposure (10-30 minutes) on measures such as aggressive emotions, cognitions, behaviors or a combination thereof, with only 1 study looking at the effects on physiological measures (Carnagey, Anderson, \& Bushman, 2007). We will start with the longterm effects studies and then describe the rest of the studies grouped by the measure they used. Bushman and Gibson (2011) asked participants to play either a violent or a non-violent videogame for 20 minutes. Participants were then sent home, with half of them asked to think about the game. The next day their aggressive behavior was tested with the white noise paradigm. Men who played the violent game and then ruminated about it were more aggressive compared to men who played the same game but did not think about it. Teng et al. (2011) asked subjects play a violent videogame for three weeks and compared them to a no-game passive control group. Participants in the experimental group showed stronger pro-violence attitudes compared to controls.

Eleven studies explored the effects of short-term exposure to videogames on subsequent aggressive behavior. Ballard and Lineberger (1999) asked participants to play violent or non-violent games. After playing the non-violent game, participants rewarded male confederates more compared to those that played the violent games. In addition, subjects used more punishment after playing the violent videogames compared to the non-violent game, especially when the punished confederate was a woman. Bartholow and Anderson (2002), Anderson and Murphy (2003), Bartholow et al. (Bartholow, Sestir, \& Davis, 2005) and Hasan et al. (Hasan, Bègue, \& Bushman, 2013) had participants play either a violent or a non-violent videogame. In all studies, exposure to the violent videogame led to an increase in aggressive behavior as measured with the white noise paradigm. In Sheese and Graziano (2005), participants played a violent or a non-violent version of the same videogame their pro- and 
anti-social behavior was tested with the prisoner's dilemma. Exposure to the violent videogame led to an increase in choosing to exploit compared to exposure to the non-violent game. Fischer et al. (Fischer, Kastenmüller, \& Greitemeyer, 2010) and Hollingdale and Greitemeyer (2013) had participants play a violent or a non-violent videogame with a pre-chosen avatar or a personalized avatar. Aggressive behavior was tested using a hot-sauce paradigm, in which the participants chose how much hot chili sauce another "participant" will have to consume. Participants in the violent videogame groups were more aggressive than the non-violent videogame groups, and the combination of playing a violent game with a personalized avatar led to the most aggressive behavior. Hollingdale and Greitemeyer (2014) exposed participants to either a violent or a non-violent videogame which was played either offline against a computer or online against a human opponent and was then followed by the hot sauce paradigm. Exposure to the violent videogame increased aggressive behavior and this was especially pronounced when playing a human opponent. Finally, Anderson and Morrow (1995) and Adachi and Willoughby (2011) explored whether aggressive behavior following videogame play was the product of competitiveness rather than exposure to violent content. In Anderson and Morrow's study (1995) subjects played a videogame in pairs either competitively or cooperatively. The measure of aggressive behavior was behaviors displayed during the game directed at the game characters. Under the competitive situation, subjects were more aggressive compared to the cooperative situation. In Adachi and Willoughby's study (2011), participants played a violent or a non-violent videogame which were matched for competitiveness and then underwent the hot sauce paradigm. There were no differences between the groups in aggressiveness, lending support to the authors hypothesis that competitiveness and not violent content was the cause of aggressive behavior. Indeed, in a follow-up experiment subjects were exposed to violent or non-violent videogames which were 
either competitive or non-competitive and aggression was elevated in the groups playing the competitive games, regardless of violent content.

Five studies tested the effects of short-term exposure to videogames using cognitive measures. Bushman and Anderson (2002) tested if exposure to violent videogames will create a hostile expectation bias when presented with ambiguous stories. Subjects played a violent or a non-violent videogame and were then presented with the stories. Those that played the violent videogame interpreted the character's behaviors, thought and feelings as more aggressive compared to those that played the non-violent videogame. Eastin and Griffiths (2006) used the same task to measure hostile expectation bias after playing a violent videogame in male players, while also testing the effects of the specific type of violence depicted, VR gaming mode as opposed to a standard game console and a human as opposed to a computer opponent. Results showed that playing a fighting game in a VR environment led to the greatest hostile expectation bias, but this bias was unaffected by the type of opponent (human or computer). Kirsh and Mounts (2005) explored whether playing a violent videogame will create an attentional negative bias. Participants played a violent or a non-violent videogame and underwent the emotional Stroop task. Those that played the violent videogame had greater Stroop interference compared to those in the non-violent game group. Eastin (2006) tested the effects of violent videogames on aggressive thoughts, while also testing how a sex match between player and avatar, the sex of the opponent and a human vs. computer opponent will influence aggressive thoughts. In the first experiment, women played a violent videogame with either a female or a male avatar against either a female or a male avatar. After the game a word completion task was used to measure aggressive thoughts. The results indicated that a sexmatch between the player and her avatar and playing against a male opponent increased aggressive thoughts compared to playing with an opposite sex avatar and playing against a female opponent. In the second experiment the same design was used, but half of the subjects 
were told they were playing against the computer while the other half were told they were playing a human female opponent. The results showed that aggressive thoughts were greater in subjects who thought they were playing a human opponent than in those who thought they were playing the computer. The third experiment used the same design, with the exception that subjects were now told that they were playing either a man, a woman or the computer. Results showed that when subjects thought they were playing against a man, aggressive thoughts increased compared to playing against a woman or the computer. Finally, Kirsh and Mounts (2007) tested if exposure to violent videogames will influence recognition of emotional faces. Participants played either a violent or a non-violent videogame and then performed a face morphing task. Subjects who played the violent videogame were slower to recognize happy faces compared to controls.

Five studies tested the effect of videogames on hostile feelings using self-report measures. Anderson and Ford (1986) asked participants to play a violent videogames, and a no-game passive control group was also included. The videogames increased hostility and anxiety compared to no-game controls. Tamborini et al. (2001) asked participants to play a violent videogame in VR mode, to play a violent videogame on a standard console, to observe a violent videogame or to observe a non-violent videogame and to write down their thoughts during the game. Fewer hostile thoughts were observed in the non-violent observation condition compared to the other three conditions. Williams and Clippinger (2002) had participants play a non-violent game first vs. the computer and a week later vs. a human opponent. Results indicated that self-reports of aggression and hostility were higher after playing the computer. Farrar et al. (Farrar, Krcmar, \& Nowak, 2006) had participants play a violent videogame either from a first- or a third-person perspective and in one of two modes: one which depicted blood spattering when someone was injured or killed in the game and one without this graphic feature. It was found that playing the game with the blood spatter option 
led to greater hostility. Finally, Eastin (2007) asked participants to play a violent videogame either competitively or cooperatively in groups varying from two to six players. Although there was no difference in hostility between cooperative and competitive play, groups size did affect this measure, with larger groups causing more hostility.

One study tested the effects of violent videogame exposure on physiological measures (Carnagey et al., 2007) in order to explore if exposure to violent videogames desensitizes people to real world violence. Subjects' GSR and heart rate (HR) were measured before and after playing a violent or a non-violent videogame. Then, they watched a video of real violence while their GSR and HR were measured again. Subjects who played the violent videogame had lower physiological arousal when watching real violence compared to controls.

Twelve studies used a combination of measures to look at the effects of videogames on aggression. Two studies (Greitemeyer, 2014; Greitemeyer \& McLatchie, 2011) tested the effects of videogame play on both cognitive and behavioral measures. In Greitemeyer and McLatchie (2011), participants played either a violent, a neutral or a pro-social videogame and filled out a questionnaire assessing their perceptions of out-group members. Exposure to the violent videogame decreased the perceived humaneness of the out-group and exposure to the pro-social game did not increase it. In addition, after supposedly being negatively evaluated by another participant, subjects exposed to the violent videogame displayed more aggressive behavior towards that participant, as measured by less willingness to recommend him for a job at the lab. Greitemeyer (2014) asked subjects to play a violent or a non-violent videogame and to rate the aggressiveness of behaviors presented as either performed by them or by someone else. After exposure to the violent videogame participants rated the aggressive acts performed by themselves as less aggressive compared to the control group. In addition, they behaved more aggressively as measured with the hot sauce paradigm. Three studies looked at measures of self-reported hostility in combination with either physiological (Ballard \& Wiest, 1996), 
behavioral (Tamborini et al., 2004) or cognitive (Schmierbach, 2010) measures. Ballard and Wiest (1996) asked men to play a violent, a very violent or a non-violent videogame and collected physiological measures (HR and blood pressure) and self-report measures of hostility. Results showed that after playing, physiological arousal and hostility was greater in subjects that played the violent videogames, especially in those exposed to the very violent game version. In addition, arousal and hostility were positively correlated. In Tamborini et al. (2004), participants either played a VR violent videogame or a standard violent videogame, or observed a violent videogame or a non-violent videogame. Hostile thoughts were measured with selfreport questionnaires and aggressive behavior was measured by asking the participants to evaluate a research assistant. Results indicated that exposure to violent videogames in all three relevant conditions increased hostility in an identical manner, but did not impact aggressive behavior. Schmierbach (2010) asked participants to play a violent videogame either solo, cooperatively or competitively and their aggressive cognitions were measured. Results indicated that competitive play increased aggressive cognitions. Three studies looked at measures of self-reported hostility in combination with cognitive and behavioral measures. In Anderson and Dill (2000), participants played a violent or a non-violent videogame. Selfreports of hostility, aggressive cognitions and aggressive behavior using the white noise paradigm were collected. Results showed that exposure to the violent videogame increased aggressive cognitions and behavior. Carnagey and Anderson (2005) asked participants to play a driving game in which violence was either rewarded or punished. A non-violent version was included as the control group. Self-reports of hostility, aggressive cognitions and aggressive behavior (evaluating another "participant") were assessed. Results showed that exposure to both versions of the violent game increased hostility and aggressive cognitions. Aggressive behavior was increased only in subjects that were rewarded for violence. Anderson and Carnagey (2009) asked participants to play a violent or a non-violent competitive sports 
videogame. Self-report measures of hostility as well as aggressive cognitions were measured and aggressive behavior was evaluated using the white noise paradigm. All three measures increased after playing the violent game. Three studies looked at measures of self-reported hostility in combination with cognitive and physiological measures. Calvert and Tan (1994) asked participants to play a violent VR videogame or to watch someone else play it. A no-game passive control group was also included. Self-reported hostility, aggressive cognitions and pulse were measured. Results showed that in the VR playing condition, arousal was increased, as well as aggressive cognitions. Hostility was unaffected. In Barlett et al. (Barlett, Harris, \& Baldassaro, 2007), participants were asked to play a violent first person shooter videogame with a standard controller and with a controller shaped like a gun. Self-report measures of hostility as well as physiological arousal (HR) and aggressive cognitions were collected a few times before, during and after playing. Results indicated that all measures were higher the longer the subject played and when playing with the gun shaped controller compared to the standard controller. Barlett at el. (Barlett, Rodeheffer, Baldassaro, Hinkin, \& Harris, 2008) asked participants to play a violent or a non-violent videogame on different consoles with varying degrees of graphic realism. Measures of self-reported hostility, aggressive cognitions and physiological arousal (HR) were collected. While physiological arousal was unaffected, hostility and aggressive cognitions were elevated in the violent videogame groups, especially in the group which played to most graphically realistic game. Finally, one study (C. A. Anderson et al., 2004) looked at behavioral, cognitive and physiological measures of aggression. In the study, subjects played a violent or a non-violent videogame and physiological arousal (HR and blood pressure) as well as aggressive cognitions and aggressive behavior (with the white noise paradigm) were assessed. Physiological arousal as well as aggressive cognitions and behavior were higher in the violent videogame group. 
Effects on stereotypes and body image. We located three studies testing the effects of videogames on stereotypes and one study testing the effects of videogames on body image, all conducted in adults. Barlett and Harris (2008) asked men to play a wrestling game against a muscular avatar and women to play a sports game depicting a super-model like female avatar. Body esteem declined from pre- to post-exposure to the avatars. In Behm-Morawitz and Mastro (2009), participants who played a videogame as a sexualized avatar reported lower selfefficacy and less favorable attitudes towards women's physical and cognitive capabilities compared to women playing a non-sexualized game or a no-game control group. Yang et al. (Yang, Gibson, Lueke, Huesmann, \& Bushman, 2014), had participants play a violent or nonviolent videogame as either a Caucasian or an African-American avatar. Playing a violent game as an African-American avatar increased negative attitudes towards African-Americans and aggressive behavior measured by the hot sauce paradigm compared to all other groups. Yang et al. (Yang, Huesmann, \& Bushman, 2014) also found that playing a violent videogame as a male avatar increased aggressive behavior in the hot sauce paradigm compared to playing as a female avatar.

Effects on cognitive abilities. We were able to locate seven studies showing null or negative effects of videogame play on cognitive abilities, of which one was conducted with children.

Studies of videogames and cognitive abilities in children. Weis and Cerankosky (2010) gave boys a videogame console or assigned them to a wait-list control group. In the intervention group reading and writing skills were stable from baseline to the end of the four-month intervention, but they increased in the control group maybe because the intervention group spent less time in afterschool academic activities due to videogame play.

Studies of videogames and cognitive abilities in adults. Fischer et al. (Fischer, Kubitzki, Guter, \& Frey, 2007) assigned participants to play either risky driving games or active non- 
risky games. Participants who played the risky games had more risk-taking promoting cognitions and were more aroused after the game and men who played the risky games performed more risky behaviors during a driving simulation. Greenfield et al. (Greenfield, Brannon, \& Lohr, 1994) and Sims and Mayer (2002) randomly assigned subjects to play a videogame requiring the use of spatial skills over a prolonged period (four or 10 weeks respectively) or to a passive no-game control group. In both studies, the intervention was found to be unsuccessful. Boot et al. (2008) trained participants for four to five weeks in either a firstperson shooter game, a strategy game or a game utilizing spatial abilities but apart from a modest improvement in mental rotation in the group that played the spatial game, no cognitive ability was improved after training. A similar design with elderly subjects failed to improve a variety of cognitive measures (perceptual speed, memory, selective attention, executive control and reasoning abilities) (Boot et al., 2013). Finally, van Ravenzwaaij et al. (2014) recruited non-gamers and trained them on an action or a non-action videogame for a total of 20 hours and their speed or processing was evaluated pre- and post-intervention. Both groups improved regardless of the kind of game they trained on.

Effects on physical fitness and nutrition. We were able to find 2 studies of the effects of videogames on physical fitness in children and 1 study on the effects of videogames on nutrition in adults.

Studies of videogames and physical fitness and nutrition in children. Graves et al. (Graves, Ridgers, Atkinson, \& Stratton, 2010) carried out a 12-week home-based intervention in which children were encouraged to play active rather than sedentary videogames. Children in the control group were instructed to keep playing with their videogame consoles as usual. Similarly, Baranowski et al. (2012) gave children a gaming console and some active or sedentary videogames and followed them for 12 weeks with no directed effort to guide the 
children's play patterns. In both studies, no difference in physical activity levels or any other relevant measure was found between the groups.

Studies of videogames and physical fitness and nutrition in adults. Oldham-Cooper et al. (Oldham-Cooper, Hardman, Nicoll, Rogers, \& Brunstrom, 2011) instructed participants to play a videogame during lunch or to eat undistracted. The subjects who played during lunch were less satiated and had impaired memory for lunch items compared to those that ate undistracted.

Effects on mood. We located one randomized controlled study testing the effects of videogames on mood. In this study (Nelson \& Carlson, 1985) adults as well as young and adolescent boys played anti-social driving games as well as pro-social games. After an extended play period, there were self-reported increases in depression, hostility, aggression and fatigue and decreases in concentration, vigor and social affection regardless of the type of game played.

\section{Mobile devices.}

Effects on cognition. We located two studies examining the effects of mobile devices on cognition, both with adult participants. In an EEG study by Mun et al. (Mun, Kim, \& Park, 2014) participants were trained on a spatial discrimination task and a working memory (WM) task. Then they watched a 3D movie on a mobile phone screen and immediately performed the same tasks. Based on self-reports of their physical condition, they were divided into fatigued and non-fatigued groups and their behavioral performance and attention-related ERP components during the spatial attention and WM tasks pre- and post-3D viewing were compared. Results showed that in the fatigued group, subjects' selective attention capabilities were impaired and this was also reflected in their EEG results. Ward et al. (Ward, Duke, Gneezy, \& Bos, 2017) asked participants to perform a working memory task as well as a fluid intelligence task while their smartphone was either in a different room, in their bag/pocket or 
on the desk next to them. Results showed that performance was impaired in the desk condition compared to the other room condition, even when the phone on the desk was completely turned off.

\section{Virtual reality (VR).}

Effects on aggression/pro-social behavior. We were able to locate one study testing the effects of a virtual reality environment on aggression (Pena, Hancock, \& Merola, 2009). Adult participants were randomly assigned to be represented by white-cloaked (good) or blackcloaked (evil) male avatars. Then, they took part in an online group discussion as to the appropriate punishment for a group member who engaged in anti-social behavior. Participants represented by black-cloaked avatars were more aggressive towards other group members and viewed attacking them more positively compared to subjects with white-cloaked avatars. In addition, male participants represented by black-cloaked avatars reported less group cohesion compared to their white-cloaked counterparts. In a second experiment, participants were randomly assigned to an avatar resembling a medical doctor (positive), a member of the $\mathrm{Ku}$ Klux Klan (KKK, negative) or an avatar with a transparent body (neutral) and underwent the Thematic Appreciation test (TAT). Subjects represented by a KKK avatar wrote stories which were more aggressive compared to the control avatars and less affiliative compared to subjects represented by a doctor avatar.

\section{TV and videogames combined.}

Effects on aggression. Only one study was found assessing the effects of TV and videogame exposure in combination on aggression. In this study (Silvern \& Williamson, 1987), children played with toys on 3 consecutive days. On the second and third days, they watched a violent TV cartoon or played a violent videogame prior to play time. Results showed that both the TV show and the videogame increased aggression during play time relative to baseline. 
Effects on physical fitness, nutrition and aggression. One study tested the effects of TV and videogames in combination on physical fitness and aggression in children. The study, designed as a long-term school-based intervention assessed the effects of reducing the cumulative time children spend using TV and videogames on physical activity and obesity (Robinson, 1999) or aggression (Robinson, Wilde, Navracruz, Haydel, \& Varady, 2001). The intervention included lessons teaching children to self-monitor and decrease media use and to be selective in selecting media content. A no-intervention school served as a control. The intervention was effective at reducing TV watching, but not videotape watching or videogame playing. The intervention decreased measures of adiposity but did not change children's physical activity levels or fitness (Robinson, 1999). Some measures of aggression were decreased in the study group compared to controls at the at the end of the intervention, so that there was a reduction in peer-ratings of aggression and in observed verbal aggression (Robinson et al., 2001).

\section{[Insert table 1 here]}

\section{Positive Effects of Screen Exposure}

TV.

Effects on aggression. We found one study showing null effects of watching violent TV content on aggression, conducted with children. In this study (Walters \& Willows, 1968) children were divided to disturbed (i.e. institutionalized for a short-term period in a psychiatric treatment center) and non-disturbed groups and watched a short TV clip of aggressive or nonaggressive toy play or of the un-played toys. Results indicated that viewing the aggressive TV clip did not lead to more aggressive play behavior with these toys subsequently, unlike the study by Bandura et al. (1963).

Effects on physical fitness and nutrition. We found one study showing null effects of watching TV on nutritional habits. In the study (Martin, Coulon, Markward, Greenway, \& 
Anton, 2009) participants completed four conditions in random order over two days: eating without TV or reading, eating while reading, eating while watching TV with food and nonfood related ads and eating while watching TV without ads. The study didn't find any effect of the different eating conditions on food intake.

Effects on mood. We were able to locate three studies testing the effects of TV clips on mood in children examining whether watching TV will reduce pre-operative anxiety in children. Thus, Mifflin et al. (Mifflin, Hackmann, \& Chorney, 2012) tested anxiety levels in children who watched a TV clip before anesthesia compared to the use of traditional distraction methods such as humor or talk. Kerimoglu et al. (Kerimoglu, Neuman, Paul, Stefanov, \& Twersky, 2013) compared the efficacy of a video-glasses apparatus to that of anti-anxiety medication and Kim et al. (Kim, Jung, Yu, \& Park, 2015) compared TV clips to parental presence or a combination of both. In Mifflin et al. (2012), TV clips were more effective than the control methods and in Kerimoglu et al. (2013) and Kim et al. (2015), they were as effective as parental presence or anti-anxiety medication.

\section{Videogames.}

Effects on aggression. We were able to find six studies showing null effects of violent videogames on aggression, three of which were carried out with children or adolescents and three with adults.

Studies showing null effects of violent videogames on aggression in children and adolescents. Both Winkel et al. (Winkel, Novak, \& Hopson, 1987) and graybill et al. (Graybill, Strawniak, Hunter, \& O’Leary, 1987) asked adolescents or children, respectively, to play a non-violent or violent videogame and tested their aggressive behavior as indicated by their willingness to help or hurt someone else. Fleming and Rick Wood (2001) had children play a non-violent paper and pencil game, a non-violent videogame or a violent videogame while 
testing their physical arousal, mood and affect. None of the studies found any effect of violent videogames on aggression in any of the measures tested.

Studies showing null effects of violent videogames on aggression in adults. Scott (1995) and Williams and Skoric (2005) asked participants to fill self-report questionnaires of levels of aggression before and after playing non-violent or violent videogames for a short or a prolonged period, respectively. Ferguson et al. (2008) had participants play a violent or a nonviolent videogame for a short period and tested their aggression indicated by the white noise paradigm. All three studies failed to find any effect of violent videogame exposure on aggression in any of the measures tested.

Effects on prosocial behavior. We found 10 studies testing the effects of videogames on prosocial behavior, all with adults. Gentile et al. (2009) and Greitemeyer and Osswald (2010) had participants play a pro-social, neutral or violent videogame and assessed pro-social behaviors towards another person. In both cases, pro-social games increased social behavior. Tear and Nielsen (2013) asked participants to play one of four games: anti-social (violent without a pro-social component), violent (with a pro-social component), pro-social (without a violent component) and non-violent (without a social component). This classification was due to the fact that some violent games include pro-social themes, and therefore the authors tried to isolate the pro-social component from the violent component. Then, participants' pro-social behavior towards another person were tested and there were no differences between the groups, i.e. anti-social and violent videogames did not diminish pro-social behaviors (on the other hand, pro-social games did not encourage them). In Greitemeyer et al. (2012) participants received a negative evaluation for a task and then played a pro-social, neutral or violent game. Their aggression towards the evaluator was then tested. Results showed that both aggressive behavior and aggressive cognitions and affect were lower in the pro-social game group compared to the neutral game group. Greitemeyer and Osswald $(2009,2011)$ asked participants to play a pro- 
social or a neutral videogame and then assessed the availability of aggressive or pro-social cognitions. In both studies participants who played the pro-social game had more pro-social and less aggressive thoughts compared to controls. Greitemeyer et al. (2010) had participants play a pro-social, a violent or a neutral videogame and read texts describing someone's misfortunes. Those who played the pro-social videogame felt less schadenfreude and more empathy after reading the stories compared to the neutral group.

Ewoldsen et al. (2012), Greitemeyer (2013) and Velez et al. (Velez, Mahood, Ewoldsen, \& Moyer-Gusé, 2014) tested if playing in a group will increase pro-social behavior compared to solitary play, even when the game was violent. Ewoldsen et al. (2012) tested if the mode of play (cooperative/competitive) or the content of the game (violence) influenced pro-social behaviors. Paired participants were assigned to direct competition (killing their partner), indirect competition (outperforming their partner), cooperation condition (cooperate with the partner in order to advance in the game) and control condition (playing alone). Participants in the cooperation condition were more cooperative in a prisoner's dilemma game compared to the other groups. Greitemeyer (2013) assigned participants to play a violent videogame alone or in cooperation with another player compared to players playing a neutral game alone. Cooperative and aggressive cognitions during the game were self-reported as well as empathy towards the misfortune of a family in a text the participants read. Participants in the single-player violent videogame condition felt less empathy than participants who played the cooperative violent videogame and the neutral videogame. In addition, participants playing the violent game in cooperation had more cooperative thoughts compared to all other conditions. Similar results were obtained when comparing cooperative neutral videogame condition to a single-player neutral videogame condition. Velez et al. (2014) paired participants with a confederate which was from their in-group or out-group. Then, the pairs played a violent 
videogame cooperatively or competitively. The main outcome was that playing cooperatively with an out-group member decreased aggression as measured by a self-report questionnaire.

Effects on mood. Three randomized controlled studies tested the effects of videogame exposure on mood, one conducted with children and the others with adults.

Studies of videogames and mood in children. Patel et al. (2006) tested whether videogames could reduce anxiety in children before surgery. They were assessed for anxiety and randomized to one of three groups: parental presence, videogame play or parental presence and anti-anxiety medication. Right before the induction of surgical anesthesia, anxiety levels were assessed again (T2). The results indicated that children playing the videogame had less anxiety at $\mathrm{T} 2$ compared to the parental presence group and were no different than the children administered the anti-anxiety medication. In addition, videogame play ameliorated the rise in anxiety from baseline to $\mathrm{T} 2$ compared to the parental presence group.

Studies of videogames and mood in adults. Ferguson and Rueda (2010) intentionally frustrated participants and then asked them to play a violent videogame as "the bad guy", as "the good guy", to play a non-violent game or to rest without playing. Then participants' aggressive behavior was tested with the white noise paradigm. Exposure to violent videogames did not affect aggressive behavior. In addition, videogame exposure had no effect on hostile feelings or depression as measured with self-report questionnaires. Using a similar design, Valadez and Ferguson (2012) asked participants to play a violent videogame, a non-violent game or a non-violent section in a violent game after being intentionally frustrated. Again, exposure to the violent videogame had no effect on hostile feelings or depression.

Effects on cognitive abilities. Studies in this section are categorized to 4 groups: effects of videogames on cognition in children and adolescents, effects of videogames on cognition in adults, videogames as a way to preserve cognitive function in the elderly and effects of videogames on neural changes. 
Studies of videogames and cognition in children and adolescents. We located three studies of videogames and cognition in children and adolescents, all related to spatial abilities. McClurg and Chaillé (1987) trained children and adolescents for 6 weeks with a videogame and demonstrated an improvement in mental rotation compared to a no-game control group. Subrahmanyam and Greenfield (1994) and De Lisi and Wolford (2002) trained children on a videogame utilizing spatial abilities or a control game for two hours or one month respectively and also found an improvement in spatial abilities compared to the control game group.

Studies of videogames and cognition in adults. We located a total of 16 studies testing how videogame exposure influences visuo-spatial abilities. Three studies explored gender differences in visuo-spatial abilities. Gagnon (1985) trained participants with videogames utilizing spatial manipulation of objects for 1 week with a no-game control group. Training improved spatial skills, but only in women. Okagaki and Frensch (1994) trained participants with a videogame utilizing spatial visualization skills for two weeks and compared them to a no-game control group. The experimental group's performance improved relative to the control group. In addition, despite gender differences in mental rotation ability pre-training, both men and women improved at the same rate after training. Feng et al. (Feng, Spence, \& Pratt, 2007) trained adults to play an action videogame or a control game for four weeks. The experimental group improved in spatial attention and mental rotation compared to the control group, with gender differences decreasing (mental rotation) or disappearing (spatial attention) from pre- to post-training. Dorval and Pépin (1986) trained subjects over four to eight weeks in a videogame utilizing spatial visualization and showed that post-training their visuo-spatial abilities were better than a no-game control group. Notably, in a different paper reporting the same study, a group of adolescents was also tested but no effect was found (Pépin \& Dorval, 1986). Greenfield et al. (Greenfield, DeWinstanley, Kilpatrick, \& Kaye, 1994) trained subjects for one week on a videogame requiring the ability to turn attention to many visual locations at once. 
Compared to a no-game control group, subjects in the training group showed an improvement in their attentional field and visual detection abilities. In a series of studies by Bavelier and colleagues (Green \& Bavelier, 2003, 2006a, 2006b, 2007; R. Li, Polat, Makous, \& Bavelier, 2009; R. Li, Polat, Scalzo, \& Bavelier, 2010) participants trained with action videogames (the training period varied from 10 days to 9 weeks) or non-action games as controls. In all studies, the experimental group showed significant improvements in visuo-spatial abilities while controls showed small to non-existent improvement. Sanchez (2012) tested if visuo-spatial training will improve performance in visuo-spatial tasks and also the ability to comprehend scientific knowledge with a visuo-spatial component. Participants underwent a 25-minute training session in which they played either an actionvideo game or a control game. Results indicated that in the experimental group, visuo-spatial abilities were improved and their understanding of a scientific assay was superior compared to controls. Wu and Spence (2013) trained subjects for 3 weeks with either a first-person shooter game, a race-driving game and a control 3d puzzle game. All groups improved in visuo-spatial abilities, but the improvement was significantly larger in the action videogame groups compared to controls. Choi and Lane (2013) trained subjects for 30 hours with a first-person shooter game, a third-person shooter game or a puzzle game. Participants in the first-person shooter group improved significantly on their visual attention abilities compared to all other groups. Finally, Li et al. (L. Li, Chen, \& Chen, 2016) trained participants with action games or a non-action game over a 3-week period. After training with action games participants visuo-motor performance was improved and this effect was still evident two to three months later.

Bejjanki et al. (2014) tested the effects of videogames on visual perceptual abilities. Participants were asked to perform a visual task before and after a 50-hour training program with an action or a non-action control videogame. Action-game players displayed greater 
improvement in their perceptual abilities compared to the control group as reflected in a better ability to "filter-out" noise from distracting stimuli during the task.

Seven studies tested the effects of videogames on executive functions or general cognitive abilities. Orosy - Fildes and Allan (1989) tested reaction time to visual stimuli immediately before and after 15 minutes of videogame play and showed that reaction times were significantly shorter after the training compared to a no-game control group. Greenfield et al. (Greenfield, Camaioni, et al., 1994) tested whether videogame training will improve the ability to understand unfamiliar scientific-technical information. Participants were randomly assigned to six experimental training groups: playing a non-violent videogame, playing the game after being thoroughly instructed about it, playing the game while filling in questionnaires assessing the development of game knowledge, playing a computerized memory game, playing a non-computerized memory game and a no-game control group. Before and after the 2-hour training, all subjects were presented with scientific-technical material and their proficiency level was assessed. The results indicated that in all videogame conditions there was an improvement in understanding the novel material presented. Barlett et al. (Barlett, Vowels, Shanteau, Crow, \& Miller, 2009) assessed participants on a battery of cognitive tests before and after 18 minutes of playing a violent or a non-violent videogame (a no-game control group was also included). All videogame groups improved in their cognitive performance regardless of game type. Green et al. (Green, Pouget, \& Bavelier, 2010) tested the effects of videogame exposure on probabilistic inference by training participants to play an action or a non-action videogame for 50 hours and testing them for probabilistic inference using a visual discrimination task. The study showed that action videogames improved this ability. In a later study, Green et al. (Green, Sugarman, Medford, Klobusicky, \& Bavelier, 2012) tested the effects of videogames on task-switching abilities. Participants were trained for 50 hours on an action game or a non-action game. Results indicated that the participants playing 
the action videogame improved in their task-switching abilities more than their non-action game-playing peers, but the effect was modest. Chiappe et al. (Chiappe, Conger, Liao, Caldwell, \& Vu, 2013) examined whether action videogames will improve multi-tasking in a high workload situation. Participants were randomly assigned to play an action videogame for 10 weeks or to a no-game control group. Results indicated that videogame training improved participants' multi-tasking abilities compared to controls. Finally, Buelow et al. (Buelow, Okdie, \& Cooper, 2015) assessed the effects of videogame training on executive functions. Subjects were assigned to play various types of videogames for 30 minutes or to a no-game control group. It was found that training led to improved performance in decision-making and problem-solving abilities compared to controls.

Studies of videogames and cognition in the elderly population. In all studies, healthy subjects aged 60 or more were evaluated cognitively before and after videogame training. Thus, Clark et al. (1987) showed that a 7-week training period improved performance on a responseselection task compared to no-game controls. Dustman et al. (1992) showed that an 11-week training period improved reaction times compared to no-game controls or controls who watched movies. Goldstein et al. showed that a 5-week training period improved reaction times and subjective well-being compared to no-game controls. Basak et al. (2008) showed that a 78-week training period had beneficial effects on task-switching, working memory, reasoning abilities and mental rotation abilities compared to a no-game control group. Stern et al. (2011) showed that a 3- month training period improved letter-number sequencing abilities compared to no-game controls. Belchior et al. (2013) trained participants on an action videogame for two to three weeks and compared them to subjects participating in a clinically validated program for cognitive training, a control videogame or a no-intervention control. Compared to the nointervention control, all three interventions led to an improvement in spatial attention abilities. Maillot et al. (2012) trained subjects with a physically active videogame over 12 weeks and 
showed an improvement in physical fitness compared to a no-intervention control group, accompanied by significant improvement in measures of executive control and processing speed. Anderson-Hanley at al. (2012) also tested the cognitive benefits of an active videogame training with a VR component lasting two months compared to training with the same game but without the VR. The results revealed a significant benefit of the exercise + VR program compared to controls (no VR) as evident in better executive functions, lower risk of clinical progression into mild cognitive impairment and a greater increase in BDNF blood levels.

Studies of videogames and cognition as reflected in neural changes. We were able to locate nine studies assessing the effects of videogames on neural changes, one with adolescents and eight with adult participants. In a study by Haier et al. (Haier, Karama, Leyba, \& Jung, 2009), adolescent girls were assigned to play a videogame utilizing visuo-spatial abilities and motor coordination over three months and compared to a no-game control group. All participants underwent an MRI/fMRI scan at the start and the end of the study. Game-play increased cortical thickness in the frontal eye fields area and in the temporal poles, areas known to take part in visuo-spatial processing and advanced perceptual analysis respectively. No significant changes in hemodynamic activity as a result of the intervention were found in the fMRI scans.

Colom et al. (2012) trained young women over four weeks in a computerized puzzle game utilizing abstract reasoning as well as spatial, verbal and numerical abilities. Before and after the training period, participants and a no-game control group underwent MRI scans. Although there were no differences in cognitive performance between the groups, the authors found an increase in gray matter in areas such as the superior frontal gyrus, right postcentral gyrus, right superior temporal gyrus and right middle occipital gyrus. However, they also found a decrease in the training group in gray matter in areas such as the right inferior frontal gyrus, right precentral and postcentral gyri and right superior temporal gyrus. Lee et al. (2012) 
conducted fMRI scans during a visuo-spatial task before and after training participants for 7-8 weeks with a complex strategy game. Training was either done gradually (i.e. game complexity increased over time) or in the standard manner (i.e. the complex game was introduced from the beginning). A control group which received 6 hours of training over all was also included. Results showed that in the gradual training group there was superior performance in the visuospatial task after training which was accompanied by less activation in brain areas related to visuo-spatial attention and goal-directed movement compared to the other groups. Voss et al. (2012) conducted fMRI scans while participants played a game before and after three to five weeks of training [the game used and methid of training was the same as in Lee et al. (2012)]. Results showed that training led to changes in brain networks involved in skill learning and retrieval in the first group compared to procedural learning and skill implementation in the second group. Wu et al. (2012) trained participants over a three-week period with either a firstperson shooter game or a three-dimensional puzzle control game. The results showed that playing the first-person shooter game led to a significant improvement in a visual attention task compared to the puzzle game. In addition, participants which were high-performers in the firstperson shooter game also displayed enhanced ERP components related to top-down allocation of attentional resources. Martinez et al. (2013) scanned women using an fMRI before and after training with various puzzle videogames over a four-week period and compared them to a nogame control group. Videogame training increased functional connectivity in various restingstate networks involved in various cognitive functions. Kühn et al. (Kühn, Gleich, Lorenz, Lindenberger, \& Gallinat, 2014) trained participants for two months with a videogame utilizing navigational abilities and strategizing and compared their MRI scan to a no-game control group. The study found gray matter increases in the videogame group in the right hippocampus, right dorsolateral pre-frontal cortex and bilaterally in the cerebellum compared to controls. Nikolaidis et al. (Nikolaidis, Voss, Lee, Vo, \& Kramer, 2014) performed fMRI scans before 
and after training participants in a videogame with a working memory component over several weeks and showed that changes in fronto-parietal brain networks as a result of training predicted improvement in a working memory task unrelated to the game. Finally, Gleich et al. (Gleich, Lorenz, Gallinat, \& Kühn, 2017) performed fMRI scans of participants while they were watching reward or punishment-related videogame cues before and after 8 weeks of training with that game and compared them to a no-game control group. Results showed that as a result of game training there were functional brain changes in areas such as the pre-frontal cortex and the hippocampus which were related to reward processing and correlated with game performance.

Effects on physical fitness. We were able to locate two studies assessing the effects of active videogames on physical fitness, one carried out with children and the other with adults.

Studies of videogames and physical fitness in children. Gao and Podlog (2012) evaluated children's physical activity levels pre- and post a 3-semester intervention in which they were assigned to play a movement-based videogame with an easy improvement goal, a difficult improvement goal and a do-your best group. Children's physical activity increased only in the goal-setting groups, especially with a difficult goal.

Studies of videogames and physical fitness in adults. Lyons et al. (Lyons, Tate, Komoski, Carr, \& Ward, 2012) had participants play active balancing or aerobic videogames which were either exercise- or entertainment-themed. Energy expenditure was higher in the aerobic games and the level of enjoyment from these games predicted energy expenditure.

[Insert table 2 here]

\section{Discussion}

Many studies have investigated relationships between exposure to screen-based technologies and psychological, behavioral and health factors. However, due the correlational nature of these studies it is hard to assess whether observed differences between groups were 
the result of screen exposure and not vice versa. In order to determine causal relationships controlled experiments in which subjects are randomly assigned into groups or a within-subject design is employed are required. This review presents 150 such experiments published in English between 1963 - 2017.

Based on the studies reviewed, it is hard to answer the question "are screens good or bad for you?". Although some studies show negative effects in areas such as social behavior, empathy, nutrition and physical fitness, others find positive influences in the same domains. Moreover, most studies do not assess the naturalistic way people are using screens in their daily lives, an inherent problem of studies being carried out in laboratory settings. In these studies, subjects are tested usually after a brief exposure to a single and specific screen-based activity chosen for them by the experimenter, and their behavior or physiological measures are assessed immediately following the intervention. However, most people's "screen routines" include long hours of screen-exposure on a daily basis and in many cases interchangeable and even simultaneous use of many devices for many activities at once (e.g. working on a laptop while texting with friends via a smartphone or watching TV and checking your Facebook feed on a tablet at the same time) (Holz, Bentley, Church, \& Patel, 2015). This is important because such practices, often referred to as "media multitasking", have been shown to have detrimental effects on attention. Thus, Gonzalez and Mark (2004) have shown that in technology-rich work places people switch between tasks or devices every three minutes on average. Mark et al. (Mark, Gonzalez, \& Harris, 2005) have also shown that after external interruptions, it takes people an average of 23 minutes to re-focus and resume the task they were involved in prior to the interruption. Similarly, Ralph et al. (Ralph, Thomson, Cheyne, \& Smilek, 2014) have shown that media multitasking is positively correlated with attentional failures during the day and increased mind-wondering in female college students. Other studies have found correlations between media multitasking and reduced psychological well-being. Thus, Becker 
et al. (Becker, Alzahabi, \& Hopwood, 2013) have found a relationship between media multitasking and depression and social anxiety in female college students even after controlling for personality traits which are associated with an increased risk to develop these disorders. Similarly, Mark et al. (Mark, Wang, \& Niiya, 2014) have shown a correlation between media multitasking, increased levels of stress and decreased positive affect in college students of both sexes. Other studies have shown similar effects of media multitasking on both psychological and social well-being of young children and adolescents (Pea et al., 2012; Rideout, Foehr, \& Roberts, 2010; but see Shih, 2013). Further studies on the effects of media multitasking on attention and well-being are needed, but, the research done so far raises major concerns about such screen-use practices which need to be addressed systematically in future studies with well controlled designs.

Another shortcoming of the studies reviewed, is that most of them still focus on "classic" screen-based uses such as watching "traditional" TV shows on an actual TV set (an activity which has been on the decline in the past years, especially among children and adolescents) (Rideout et al., 2010; Stempel, Hargrove, \& Bernt, 2000), as opposed to consuming internet-based content through mobile devices and platforms such as Facebook, You-Tube, Vimeo etc. Other studies assess the effects of activities which are no doubt very popular, but are usually carried-out by a very specific audience, such as videogames played on consoles, an activity which is mostly characteristic of men (Lucas \& Sherry, 2004; Ogletree \& Drake, 2007; Phillips, Rolls, Rouse, \& Griffiths, 1995). While these studies are very informative in relation to the specific technology and/or population group they address, it is not clear what general conclusions we can draw from them regarding other uses of screens and other populations.

Another issue which is so far lacking in studies of screen use is the developmental aspect of exposure to screens. Children born in the last two decades are surrounded by screens 
from infancy, with very young children having access to their parents' mobile devices or even owning such devices. Screen-use increases with age, and as children get older, screens are incorporated into more and more areas of their daily lives: as part of their schoolwork, for social purposes or as a form of entertainment. Given that the brain develops until the age of about 21 (Giedd et al., 2015; Raznahan et al., 2012), and that the early years and adolescent period are formative years both at the psychological and at the neural level, highly influenced by the environment (Crews et al., 2007; Dawson et al., 2000; Fox et al., 2010; Hensch \& Bilimoria, 2012; McEwen, 2012; Somerville et al., 2010), it is important to examine the effects of screen-use with longitudinal and developmental experimental designs, from childhood to adulthood. This will allow us to assess the developmental influences of screen use on children's cognitive, social, emotional and physical development.

The diffuse and versatile nature of the way we use screens and the magnitude of the penetration of these technologies into human society poses a major hardship for researchers striving to evaluate their influence. One of the biggest challenges is to design experiments which represent our technology-rich environment and the way we use it while at the same time using experimental designs which allow for cause and effect conclusions and use proper control groups. We believe that one setting which allows for such designs is school. More and more schools are incorporating screen-based technologies as part of the academic curriculum (e.g. Aagaard, 2017; Piehler, 2015; Tondeur, De Bruyne, Van Den Driessche, McKenney, \& Zandvliet, 2015), and proper studies can and should be performed in order to assess how this influences children's performance in the academic, social, emotional and physical domains. The advantage of the school setting is that screen-use in classes is supervised and highly regulated by teachers, and therefore should be quite similar across class pupils. In addition, because school attendance is mostly mandatory, it is feasible to follow pupils for the whole school year or even for a few consecutive years in order to get a long-term assessment of their 
development. Finally, other classrooms in the same school and of children of the same age which will not be incorporating screen-based technologies as part of their curriculum can and should be used as control groups if we want to truly assess how screen-based education influences children's development.

It is important to remember that even if future studies show that screen-use in itself is not harmful, the many hours we spend using screens come at the expense of other activities which are essential to our well-being. Engaging in physical activity and sports (Janssen \& Leblanc, 2010; Penedo \& Dahn, 2005; Ussher, Owen, Cook, \& Whincup, 2007; Wen et al., 2011), having meaningful social interactions with family and friends (Adams, Leibbrandt, \& Moon, 2011; Helliwell \& Putnam, 2004), playing actively and in physical proximity with other children (as opposed to playing online games with people who are not physically close) (S. E. Anderson, Economos, \& Must, 2008; Ginsburg, 2007; Milteer, Ginsburg, \& Mulligan, 2012), spending time outdoors (Bowler, Buyung-Ali, Knight, \& Pullin, 2010; Zhang, Howell, \& Iyer, 2014), using mental training exercises aimed at enhancing and regulating attentional abilities (e.g. mindfulness meditation) (Davidson \& Mcewen, 2012; Davis \& Hayes, 2011; Keng, Smoski, \& Robins, 2011) and sleeping well (Buysse, 2014; Laposky, Van Cauter, \& DiezRoux, 2016; Luyster, Strollo, Zee, \& Walsh, 2012) are all activities which have been shown to contribute crucially to the well-being and optimal development of children and adults. Spending a major part of our day in front of screens necessarily minimizes the amount of time we devote to these activities, which can take a toll on our bodies and minds. In this regard, screen exposure has already been shown not only to diminish sleep time, but also sleep quality (Carter et al., 2016; Hysing et al., 2015; Twenge et al., 2017). This is explained by exposure to light which disrupts the normal secretion of melatonin, a hormone which is crucial for sleep quality (Van Der Lely et al., 2015; West et al., 2011; Wood, Rea, Plitnick, \& Figueiro, 2013) and by elevating arousal prior to bed-time (Cain \& Gradisar, 2010; Gellis \& Lichstein, 2009; 
Higuchi, Motohashi, Liu, \& Maeda, 2005). In this regard, there are still two important research questions that need to be answered. The first is to better understand the trade-off between the positive and negative effects of screen-use: Can screen-based activities contribute positively in certain domains (e.g. active videogame playing enhances cognitive and executive functions) but at the same time undermine the proper development of other skills in different domains (e.g., the same videogames, if they are of a violent nature, impair social abilities, or if they are inactive, can contribute to a sedentary lifestyle)? A second, and related issue, is whether we can do something to proactively "compensate" for the fact that some abilities might be impaired or might not develop properly due to screen-based activities. For example, can we use specific interventions aimed at promoting pro-social behaviors or an active lifestyle to offset the negative effects of screen-use in these domains?

It is naïve and unrealistic to believe we can keep children away from screens completely. Moreover, it is unwanted because screen-based technologies offer a wealth of knowledge at the stroke of a keyboard which would have been unimaginable only two decades ago. This has opened many opportunities for education even for children and youth living in remote or underprivileged places which would have had little to no access to quality education before the internet. In addition, proficiency in the use of screen-based technologies is a prerequisite for living in the modern world and finding employment. However, even based on the current scientific literature, which is still wanting, we feel that there is room for concern due to the largely unregulated use of screens, especially in young children. Here, again, we believe that the school setting can be an important platform for planning, carrying out and assessing the efficacy of interventions aimed at regulating children's use of screens, including efforts to educate children about the importance of balancing screen-time with other beneficial activities, to limit exposure-time according to recommendations of public health authorities and to mediate exposure to different types of content (i.e. violent content, content which may 
create unhealthy or unrealistic notions about self and others etc.). Ideally, such interventions should also include parental education about the effects of screens on children's development, so that its principles are also implemented at home. A good example for such an intervention are the studies by Robinson and colleagues (Robinson, 1999; Robinson et al., 2001) which were described earlier, in which children underwent a lengthy school-based program aimed at limiting media consumption and raising awareness of the quality of content consumed. This program led to a decrease in aggressiveness and a somewhat modest improvement in physical fitness. Although the results of this specific intervention were not very robust, such evidencebased initiatives should be encouraged.

Another interesting question that arises is not only when and how much we should use screens, but also how we should use them to minimize harmful effects and maximize benefits. This point is well-demonstrated by the case of violent videogames. As our review shows, while violent videogames have been found to increase aggression (e.g. Greitemeyer, 2014; Kirsh, 1998; Konijn et al., 2007; Teng et al., 2011), when played under cooperative conditions, they exerted the opposite effect, enhancing pro-social behavior (Ewoldsen et al., 2012; Greitemeyer, 2013; Velez et al., 2014). This means that cooperative screen-use might exert a buffering effect from possible negative influences of exposure to violent content, thus enabling us to develop "healthier" screen-use habits. With regards to cooperative screen-use, the question of the necessity of the players being physically rather than virtually present with one another also arises, as recent studies show that the actual presence of someone near you (Golland, Arzouan, \& Levit-Binnun, 2015) or the ability to directly establish eye-contact or mimic those around you are detrimental for the quality of interpersonal interactions (Hari, Himberg, Nummenmaa, Hämäläinen, \& Parkkonen, 2013; Leong et al., 2017). Studies exploring questions such as what are healthy screen-use habits or is physical presence necessary for meaningful social interactions during screen-use are crucial if science is to be used in order to inform policy 
makers responsible for issuing evidence-based health recommendations regarding screen exposure. Another point worth raising in the context of how we use our screen-based devices is the kind of content we consume and how we interact with it. It is not clear today if and how different uses of the same screen affect us. For example, attention-wise, is there a difference between using a tablet or a smartphone for reading a book or listening to music as opposed to using it for interacting on social networks, texting or using the internet? In the first case, attention will be focused on one activity for a prolonged period of time, while in the second case, it will be used for rapidly scanning content and moving on. Neuroscience has shown that attentional abilities are dependent upon an interplay between various brain networks, some of which allow us to stay focused on one object, and the others allow us to detect stimuli around us which call for a repeated and rapid re-orienting of our attention (Petersen \& Posner, 2012). Because of brain plasticity, the way we activate these attentional networks can strengthen or weaken their efficacy (Slagter, Davidson, \& Lutz, 2011; Slagter et al., 2007). Thus, it might be that certain strategies of screen-use which activate attentional networks in a well-balanced manner can support and even enhance attentional abilities. On the other hand, screen use which activates only some of these networks at the expense of others can be harmful. Currently, there are no studies which answer these questions.

A final point is the use of screens by specific populations which are especially vulnerable to harm derived from the use of screens. These include people with attentional disorders (ADHD/ADD). Because studies have shown that media multitasking has negative effects on cognitive control, academic performance, emotional functioning and sleep (Reviewed in Van Der Schuur, Baumgartner, Sumter, \& Valkenburg, 2015), and because these domains are especially relevant when it comes to people suffering from attentional disorders, it is especially important to study the effects of screen exposure in people with attentional deficits. A second group of potentially-vulnerable people are those prone to addiction. 
Although internet addiction is a somewhat controversial term (Guertler et al., 2014), studies have shown that internet use can become compulsive/addictive in the sense that one is not able to stop using the internet, that this use interferes with other daily duties and activities and that there is a constant preoccupation with it (Beard \& Wolf, 2001). As with other addictions, it seems that compulsive internet use is mediated by both personal (e.g. certain personality traits) and environmental (e.g. social status) factors (Van Der Aa et al., 2009). Thus, as in the case of people with attentional deficits, it is especially important to identify susceptible individuals and study the effects of exposure to screens on their well-being. Interestingly, it has been shown that there is a link between ADHD and proneness to internet and videogame addiction (Weinstein, Yaacov, Manning, Danon, \& Weizman, 2015).

\section{Limitations}

Our review has several limitations. First, choosing to focus on randomized controlled trials excludes a major body of correlational studies which we did not review. This strategy was chosen because our goal was to try and understand how screen-use influences us. Thus, we felt that studies using experimental manipulations with proper randomization and controls are best-suited to answer this research question. Second, we searched only one database, namely Pubmed. However, due to the amount of studies located using the combination of the initial search query and the "snowball" method (150) and their year span (54 years), and due to the fact that PMC is one of the biggest scientific databases in English, we feel that our review genuinely reflects the state of the art scientific knowledge regarding the effects of screen-use.

\section{Conclusion}

In this paper, we tried to review the current state of knowledge based on randomized controlled studies regarding the possible damages and benefits of using screens. We aimed to answer the question "at the end of the day, are screens good or bad for you?", a question which is becoming more and more crucial as screens proliferate and become more and more 
embedded in our lives. We feel that the current state of knowledge leaves this question unanswered. Indeed, studying screen use in ways which are as close as possible to the way we use them in our lives is complex. However, there is an urgent need for just such studies, preferably using randomized controlled designs, with an emphasis on children and adolescents. This will allow us to understand how screen-based technologies influence us for better or worse and to devise evidence-based recommendations, interventions and habits which will maximize the benefits and minimize the damages related to screen-use, thus contributing to and even enhancing our well-being.

\section{Conflict of interest statement}

The authors declare no conflict of interest.

\section{References}

Aagaard, J. (2017). Breaking down barriers: The ambivalent nature of technologies in the classroom. New Media and Society, 19(7), 1127-1143. https://doi.org/10.1177/1461444816631505

Adachi, P. J. C., \& Willoughby, T. (2011). The effect of video game competition and violence on aggressive behavior: Which characteristic has the greatest influence? Psychology of Violence, 1(4), 259-274. https://doi.org/10.1037/a0024908

Adams, K. B., Leibbrandt, S., \& Moon, H. (2011). A critical review of the literature on social and leisure activity and wellbeing in later life. Ageing and Society. https://doi.org/10.1017/S0144686X10001091

AdReaction Marketing in a multiscreen world Global Report. (2014). Retrieved from https://www.millwardbrown.com/adreaction/2014/report/Millward-Brown_AdReaction2014_Global.pdf

Anderson-Hanley, C., Arciero, P. J., Brickman, A. M., Nimon, J. P., Okuma, N., Westen, S. 
C., ... Zimmerman, E. A. (2012). Exergaming and older adult cognition: A cluster randomized clinical trial. American Journal of Preventive Medicine, 42(2), 109-119. https://doi.org/10.1016/j.amepre.2011.10.016

Anderson, C. A. (1997). Effects of violent movies and trait hostility on hostile feelings and aggressive thoughts. Aggressive Behavior, 23(May 1996), 161-178. https://doi.org/10.1002/(SICI)1098-2337(1997)23:3<161::AID-AB2>3.0.CO;2-P

Anderson, C. A., \& Carnagey, N. L. (2009). Causal effects of violent sports video games on aggression: Is it competitiveness or violent content? Journal of Experimental Social Psychology, 45(4), 731-739. https://doi.org/10.1016/j.jesp.2009.04.019

Anderson, C. A., Carnagey, N. L., Flanagan, M., Benjamin, A. J., Eubanks, J., \& Valentine, J. C. (2004). Violent Video Games: Specific Effects of Violent Content on Aggressive Thoughts and Behavior. Advances in Experimental Social Psychology, 36, 199-249. https://doi.org/10.1016/S0065-2601(04)36004-1

Anderson, C. A., \& Dill, K. E. (2000). Video games and aggressive thoughts, feelings, and behavior in the laboratory and in life. Journal of Personality and Social Psychology, 78(4), 772-790. https://doi.org/10.1037/0022-3514.78.4.772

Anderson, C. A., \& Ford, C. M. (1986). Affect of the Game Player Short-Term Effects of Highly and Mildly Aggressive Video Games. Personality and Social Psychology Bulletin, 12(4), 390-402. https://doi.org/10.1177/0146167286124002

Anderson, C. A., Ihori, N., Bushman, B. J., Rothstein, H. R., Shibuya, A., Swing, E. L., ... Saleem, M. (2010). Violent video game effects on agression, empathy, and prosocial behavior in Eastern and Wester countries: A meta-analytic review. Psychological Bulletin. American Psychological Association. https://doi.org/10.1037/a0018251 Anderson, C. A., \& Morrow, M. (1995). Competitive Aggression without Interaction: Effects of Competitive Versus Cooperative Instructions on Aggressive Behavior in Video 
Games. Personality and Social Psychology Bulletin, 21(10), 1020-1030.

https://doi.org/10.1177/01461672952110003

Anderson, C. A., \& Murphy, C. R. (2003). Violent Video Games and Aggressive Behavior in Young Women. Aggressive Behavior, 29(5), 423-429. https://doi.org/10.1002/ab.10042

Anderson, S. E., Economos, C. D., \& Must, A. (2008). Active play and screen time in US children aged 4 to 11 years in relation to sociodemographic and weight status characteristics: A nationally representative cross-sectional analysis. BMC Public Health, 8. https://doi.org/10.1186/1471-2458-8-366

Bale, T. L. (2015). Epigenetic and transgenerational reprogramming of brain development. Nature Reviews Neuroscience. Nature Publishing Group. https://doi.org/10.1038/nrn3818

Ballard, M. E., \& Lineberger, R. (1999). Video game violence and confederate gender: Effects on reward and punishment given by college males. Sex Roles, 41(7-8), 541-558. https://doi.org/10.1023/A:1018843304606

Ballard, M. E., \& Wiest, J. R. (1996). Mortal Kombat (tm): The Effects of Violent Videogame Play on Males' Hostility and Cardiovascular Responding1. Journal of Applied Social Psychology, 26(8), 717-730. https://doi.org/10.1111/j.15591816.1996.tb02740.x

Bandura, A., Ross, D., \& Ross, S. A. (1963). Imitation of film-mediated aggressive models. Journal of Abnormal and Social Psychology, 66(1), 3-11. https://doi.org/10.1037/h0048687

Baranowski, T., Abdelsamad, D., Baranowski, J., O’Connor, T. M., Thompson, D., Barnett, A., ... Chen, T.-A. (2012). Impact of an active video game on healthy children's physical activity. Pediatrics, 129(3), e636-42. https://doi.org/10.1542/peds.2011-2050

Barlett, C., \& Harris, R. J. (2008). The impact of body emphasizing video games on body 
image concerns in men and women. Sex Roles, 59(7-8), 586-601. https://doi.org/10.1007/s11199-008-9457-8

Barlett, C., Harris, R. J., \& Baldassaro, R. (2007). Longer you play, the more hostile you feel: Examination of first person shooter video games and aggression during video game play. Aggressive Behavior, 33(6), 486-497. https://doi.org/10.1002/ab.20227

Barlett, C., Rodeheffer, C. D., Baldassaro, R., Hinkin, M. P., \& Harris, R. J. (2008). The effect of advances in video game technology and content on aggressive cognitions, hostility, and heart rate. Media Psychology, 11(4), 540-565. https://doi.org/10.1080/15213260802492018

Barlett, C., Vowels, C. L., Shanteau, J., Crow, J., \& Miller, T. (2009). The effect of violent and non-violent computer games on cognitive performance. Computers in Human Behavior, 25(1), 96-102. https://doi.org/10.1016/j.chb.2008.07.008

Bartholow, B. D., \& Anderson, C. A. (2002). Effects of violent video games on aggressive behavior: Potential sex differences. Journal of Experimental Social Psychology, 38(3), 283-290. https://doi.org/10.1006/jesp.2001.1502

Bartholow, B. D., Sestir, M. A., \& Davis, E. B. (2005). Correlates and consequences of exposure to video game violence: Hostile personality, empathy, and aggressive behavior. Personality and Social Psychology Bulletin, 31(11), 1573-1586. https://doi.org/10.1177/0146167205277205

Basak, C., Boot, W. R., Voss, M. W., \& Kramer, A. F. (2008). Can training in a real-time strategy video game attenuate cognitive decline in older adults? Psychol Aging, 23(4), 765-777. https://doi.org/2008-19072-010 [pii]\r10.1037/a0013494

Bavelier, D., Green, C. S., \& Dye, M. W. G. (2010). Children, Wired: For Better and for Worse. Neuron, 67(5), 692-701. https://doi.org/10.1016/j.neuron.2010.08.035

Bavelier, D., Green, C. S., Pouget, A., \& Schrater, P. (2012). Brain Plasticity Through the 
Life Span: Learning to Learn and Action Video Games. Annual Review of Neuroscience, 35(1), 391-416. https://doi.org/10.1146/annurev-neuro-060909-152832

Beard, K. W., \& Wolf, E. M. (2001). Modification in the Proposed Diagnostic Criteria for Internet Addiction. CyberPsychology \& Behavior, 4(3), 377-383. https://doi.org/10.1089/109493101300210286

Becker, M. W., Alzahabi, R., \& Hopwood, C. J. (2013). Media Multitasking Is Associated with Symptoms of Depression and Social Anxiety. Cyberpsychology, Behavior, and Social Networking, 16(2), 132-135. https://doi.org/10.1089/cyber.2012.0291

Behm-Morawitz, E., \& Mastro, D. (2009). The effects of the sexualization of female video game characters on gender stereotyping and female self-concept. Sex Roles, 61(11-12), 808-823. https://doi.org/10.1007/s11199-009-9683-8

Bejjanki, V. R., Zhang, R., Li, R., Pouget, A., Green, C. S., Lu, Z.-L., \& Bavelier, D. (2014). Action video game play facilitates the development of better perceptual templates. Proceedings of the National Academy of Sciences, 111(47), 16961-16966. https://doi.org/10.1073/pnas.1417056111

Belchior, P., Marsiske, M., Sisco, S. M., Yam, A., Bavelier, D., Ball, K., \& Mann, W. C. (2013). Video game training to improve selective visual attention in older adults.

Computers in Human Behavior, 29(4), 1318-1324.

https://doi.org/10.1016/j.chb.2013.01.034

Bleakley, C. M., Charles, D., Porter-Armstrong, A., McNeill, M. D. J., McDonough, S. M., \& McCormack, B. (2013). Gaming for Health: A Systematic Review of the Physical and Cognitive Effects of Interactive Computer Games in Older Adults. Journal of Applied Gerontology, 34(3), 0733464812470747--0733464812470747-. https://doi.org/10.1177/0733464812470747

Blumberg, F. C., Altschuler, E. A., Almonte, D. E., \& Mileaf, M. I. (2013). The impact of 
recreational video game play on children's and adolescents' cognition. New Directions for Child and Adolescent Development, 2013(139), 41-50.

https://doi.org/10.1002/cad.20030

Boot, W. R., Champion, M., Blakely, D. P., Wright, T., Souders, D. J., \& Charness, N. (2013). Video Games as a Means to Reduce Age-Related Cognitive Decline: Attitudes, Compliance, and Effectiveness. Frontiers in Psychology, 4. https://doi.org/10.3389/fpsyg.2013.00031

Boot, W. R., Kramer, A. F., Simons, D. J., Fabiani, M., \& Gratton, G. (2008). The effects of video game playing on attention, memory, and executive control. Acta Psychologica, 129(3), 387-398. https://doi.org/10.1016/j.actpsy.2008.09.005

Boulos, R., Vikre, E. K., Oppenheimer, S., Chang, H., \& Kanarek, R. B. (2012, August 20). ObesiTV: How television is influencing the obesity epidemic. Physiology and Behavior. Elsevier. https://doi.org/10.1016/j.physbeh.2012.05.022

Bowler, D. E., Buyung-Ali, L. M., Knight, T. M., \& Pullin, A. S. (2010). A systematic review of evidence for the added benefits to health of exposure to natural environments. BMC Public Health, 10. https://doi.org/10.1186/1471-2458-10-456

Boyle, E. A., Hainey, T., Connolly, T. M., Gray, G., Earp, J., Ott, M., ... Pereira, J. (2016). An update to the systematic literature review of empirical evidence of the impacts and outcomes of computer games and serious games. Computers and Education, 94, 178 192. https://doi.org/10.1016/j.compedu.2015.11.003

Brockmyer, J. F. (2015). Playing Violent Video Games and Desensitization to Violence. Child and Adolescent Psychiatric Clinics of North America, 24(1), 65-77. https://doi.org/10.1016/j.chc.2014.08.001

Bucksch, J., Sigmundova, D., Hamrik, Z., Troped, P. J., Melkevik, O., Ahluwalia, N., ... Inchley, J. (2016). International Trends in Adolescent Screen-Time Behaviors from 
2002 to 2010. Journal of Adolescent Health, 58(4), 417-425.

https://doi.org/10.1016/j.jadohealth.2015.11.014

Buelow, M. T., Okdie, B. M., \& Cooper, A. B. (2015). The influence of video games on executive functions in college students. Computers in Human Behavior, 45, 228-234. https://doi.org/10.1016/j.chb.2014.12.029

Bushman, B. J. (1998). Priming effects of media violence on the accessibility of aggressive constructs in memory. Personality and Social Psychology Bulletin, 24(5), 537-545. https://doi.org/10.1177/0146167298245009

Bushman, B. J., \& Anderson, C. A. (2002). Violent video games and hostile expectations: A test of the general aggression model. Personality and Social Psychology Bulletin, 28(12), 1679-1686. https://doi.org/10.1177/014616702237649

Bushman, B. J., \& Bonacci, A. M. (2002). Violence and sex impair memory for television ads. Journal of Applied Psychology, 87(3), 557-564. https://doi.org/10.1037//00219010.87.3.557

Bushman, B. J., \& Geen, R. G. (1990). Role of cognitive-emotional mediators and individual differences in the effects of media violence on aggression. Journal of Personality and Social Psychology, 58(1), 156-163. https://doi.org/10.1037//0022-3514.58.1.156

Bushman, B. J., \& Gibson, B. (2011). Violent video games cause an increase in aggression long after the game has been turned off. Social Psychological and Personality Science, 2(1), 29-32. https://doi.org/10.1177/1948550610379506

Buysse, D. J. (2014). Sleep Health: Can We Define It? Does It Matter? Sleep, 37(1), 9-17. https://doi.org/10.5665/sleep.3298

Cain, N., \& Gradisar, M. (2010). Electronic media use and sleep in school-aged children and adolescents: A review. Sleep Medicine. https://doi.org/10.1016/j.sleep.2010.02.006

Calvert, S. L., \& Tan, S. L. (1994). Impact of virtual reality on young adults' physiological 
arousal and aggressive thoughts: Interaction versus observation. Journal of Applied Developmental Psychology, 15(1), 125-139. https://doi.org/10.1016/01933973(94)90009-4

Carnagey, N. L., \& Anderson, C. A. (2005). The effects of reward and punishment in violent video games on aggressive affect, cognition, and behavior. Psychological Science, 16(11), 882-889. https://doi.org/10.1111/j.1467-9280.2005.01632.x

Carnagey, N. L., Anderson, C. A., \& Bushman, B. J. (2007). The effect of video game violence on physiological desensitization to real-life violence. Journal of Experimental Social Psychology, 43(3), 489-496. https://doi.org/10.1016/j.jesp.2006.05.003

Caroli, M., Argentieri, L., Cardone, M., \& Masi, A. (2004). Role of television in childhood obesity prevention. International Journal of Obesity and Related Metabolic Disorders : Journal of the International Association for the Study of Obesity, 28 Suppl 3, S104S108. https://doi.org/10.1038/sj.ijo.0802802

Carter, B., Rees, P., Hale, L., Bhattacharjee, D., \& Paradkar, M. S. (2016, December 1). Association between portable screen-based media device access or use and sleep outcomes a systematic review and meta-analysis. JAMA Pediatrics. American Medical Association. https://doi.org/10.1001/jamapediatrics.2016.2341

Chambers, J. H., \& Ascione, F. R. (1987). The Effects of Prosocial and Aggressive Videogames on Children's Donating and Helping. Journal of Genetic Psychology, 148(4), 499-505. https://doi.org/10.1080/00221325.1987.10532488

Chan, P. A., \& Rabinowitz, T. (2006). A cross-sectional analysis of video games and attention deficit hyperactivity disorder symptoms in adolescents. Annals of General Psychiatry, 5(1), 16. https://doi.org/10.1186/1744-859X-5-16

Chiappe, D., Conger, M., Liao, J., Caldwell, J. L., \& Vu, K. P. L. (2013). Improving multitasking ability through action videogames. Applied Ergonomics, 44(2), 278-284. 
https://doi.org/10.1016/j.apergo.2012.08.002

Children and Parents: Media Use and Attitudes Report. (2014). Retrieved from

http://stakeholders.ofcom.org.uk/binaries/research/media-literacy/media-use-attitudes14/Childrens_2014_Report.pdf

Choi, H., \& Lane, S. A. (2013). Impact of visuospatial characteristics of video games on improvements in cognitive abilities. In Proceedings of the Human Factors and Ergonomics Society (pp. 1735-1739). https://doi.org/10.1177/1541931213571387

Clark, J. E., Lanphear, A. K., \& Riddick, C. C. (1987). The effects of videogame playing on the response selection processing of elderly adults. Journals of Gerontology, 42(1), 8285. https://doi.org/10.1093/geronj/42.1.82

Colom, R., Quiroga, M. Á., Solana, A. B., Burgaleta, M., Román, F. J., Privado, J., ... Karama, S. (2012). Structural changes after videogame practice related to a brain network associated with intelligence. Intelligence, 40(5), 479-489. https://doi.org/10.1016/j.intell.2012.05.004

Cooper, J., \& Mackie, D. (1986). Video Games and Aggression in Children. Journal of Applied Social Psychology, 16(8), 726-744. https://doi.org/10.1111/j.15591816.1986.tb01755.x

Crews, F., He, J., \& Hodge, C. (2007, February 1). Adolescent cortical development: A critical period of vulnerability for addiction. Pharmacology Biochemistry and Behavior. Elsevier. https://doi.org/10.1016/j.pbb.2006.12.001

Davidson, R. J., \& Mcewen, B. S. (2012). Social influences on neuroplasticity: stress and interventions to promote well-being. Nature Neuroscience. https://doi.org/10.1038/nn.3093

Davis, D. M., \& Hayes, J. A. (2011). What Are the Benefits of Mindfulness? A Practice Review of Psychotherapy-Related Research. Psychotherapy. 
https://doi.org/10.1037/a0022062

Dawson, G., Ashman, S. B., \& Carver, L. J. (2000). The role of early experience in shaping behavioral and brain development and its implications for social policy. Development and Psychopathology, 12(4), S0954579400004089.

https://doi.org/10.1017/S0954579400004089

De Lisi, R., \& Wolford, J. L. (2002). Improving children's mental rotation accuracy with computer game playing. Journal of Genetic Psychology, 163(3), 272-282. https://doi.org/10.1080/00221320209598683

Dorval, M., \& Pépin, M. (1986). Effect of playing a video game on a measure of spatial visualization. Perceptual Motor Skills, 62, 159-162. https://doi.org/10.2466/pms.1986.62.1.159

Dustman, R. E., Emmerson, R. Y., Steinhaus, L. a, Shearer, D. E., \& Dustman, T. J. (1992). The effects of videogame playing on neuropsychological performance of elderly individuals. Journal of Gerontology, 47(3), P168-71. https://doi.org/Cited By (since 1996) 14\nExport Date 14 February 2012

Eastin, M. S. (2006). Video game violence and the female game player: Self- and opponent gender effects on presence and aggressive thoughts. Human Communication Research, 32(3), 351-372. https://doi.org/10.1111/j.1468-2958.2006.00279.x

Eastin, M. S. (2007). The influence of competitive and cooperative group game play on state hostility. Human Communication Research, 33(4), 450-466. https://doi.org/10.1111/j.1468-2958.2007.00307.x

Eastin, M. S., \& Griffiths, R. P. (2006). Beyond the shooter game: Examining presence and hostile outcomes among male game players. Communication Research, 33(6), 448-466. https://doi.org/10.1177/0093650206293249

Ellis, B. J., Boyce, W. T., Belsky, J., Bakermans-Kranenburg, M. J., \& Van Ijzendoorn, M. 
H. (2011). Differential susceptibility to the environment: An evolutionaryneurodevelopmental theory. Development and Psychopathology, 23(1), 7-28. https://doi.org/10.1017/S0954579410000611

Ewoldsen, D. R., Eno, C. A., Okdie, B. M., Velez, J. A., Guadagno, R. E., \& DeCoster, J. (2012). Effect of Playing Violent Video Games Cooperatively or Competitively on Subsequent Cooperative Behavior. Cyberpsychology, Behavior, and Social Networking, 15(5), 277-280. https://doi.org/10.1089/cyber.2011.0308

Farrar, K. M., Krcmar, M., \& Nowak, K. L. (2006). Contextual features of violent video games, mental models, and aggression. Journal of Communication, 56(2), 387-405. https://doi.org/10.1111/j.1460-2466.2006.00025.x

Feng, J., Spence, I., \& Pratt, J. (2007). Playing an action video game reduces gender differences in spatial cognition. Psychological Science, 18(10), 850-855. https://doi.org/10.1111/j.1467-9280.2007.01990.x

Ferguson, C. J., \& Rueda, S. M. (2010). The Hitman study: Violent video game exposure effects on aggressive behavior, hostile feelings, and depression. In European Psychologist (Vol. 15, pp. 99-108). https://doi.org/10.1027/1016-9040/a000010

Ferguson, C. J., Rueda, S. M., Cruz, A. M., Ferguson, D. E., Fritz, S., \& Smith, S. M. (2008). Violent video games and aggression: Causal relationship or byproduct of family violence and intrinsic violence motivation? Criminal Justice and Behavior, 35(3), 311332. https://doi.org/10.1177/0093854807311719

Ferguson, T., Berlin, J., Noles, E., Johnson, J., Reed, W., \& Spicer, C. V. (2005). Variation in the application of the "promiscuous female" stereotype and the nature of the application domain: Influences on sexual harassment judgments after exposure to the Jerry Springer Show. Sex Roles, 52(7-8), 477-487. https://doi.org/10.1007/s11199-005-3713-y

Fischer, P., Kastenmüller, A., \& Greitemeyer, T. (2010). Media violence and the self: The 
impact of personalized gaming characters in aggressive video games on aggressive behavior. Journal of Experimental Social Psychology, 46(1), 192-195.

https://doi.org/10.1016/j.jesp.2009.06.010

Fischer, P., Kubitzki, J., Guter, S., \& Frey, D. (2007). Virtual driving and risk taking: Do racing games increase risk-taking cognitions, affect, and behaviors? Journal of Experimental Psychology: Applied, 13(1), 22-31. https://doi.org/10.1037/1076898X.13.1.22

Fleming, M. J., \& Rick Wood, D. J. (2001). Effects of Violent Versus Nonviolent Video Games on Children's Arousal, Aggressive Mood, and Positive Mood. Journal of Applied Social Psychology, 31(10), 2047-2071. https://doi.org/10.1111/j.15591816.2001.tb00163.x

Fox, S. E., Levitt, P., \& Nelson, C. A. (2010, January 1). How the timing and quality of early experiences influence the development of brain architecture. Child Development. Blackwell Publishing Ltd. https://doi.org/10.1111/j.1467-8624.2009.01380.x

Gagnon, D. (1985). Videogames and spatial skills: An exploratory study. Educational Communication and Technology, 33(4), 263-275. https://doi.org/10.1007/BF02769363

Gao, Z., \& Podlog, L. (2012). Urban Latino children's physical activity levels and performance in interactive dance video games: Effects of goal difficulty and goal specificity. Archives of Pediatrics and Adolescent Medicine, 166(10), 933-937. https://doi.org/10.1001/archpediatrics.2012.649

Gellis, L. A., \& Lichstein, K. L. (2009). Sleep Hygiene Practices of Good and Poor Sleepers in the United States: An Internet-Based Study. Behavior Therapy, 40(1), 1-9. https://doi.org/10.1016/j.beth.2008.02.001

Gentile, D. A., Anderson, C. A., Yukawa, S., Ihori, N., Saleem, M., Ming, L. K., ... Sakamoto, A. (2009). The effects of prosocial video games on prosocial behaviors: 
International evidence from correlational, longitudinal, and experimental studies.

Personality and Social Psychology Bulletin, 35(6), 752-763.

https://doi.org/10.1177/0146167209333045

Gentile, D. A., Swing, E. L., Lim, C. G., \& Khoo, A. (2012). Video game playing, attention problems, and impulsiveness: Evidence of bidirectional causality. Psychology of Popular Media Culture, 1(1), 62-70. https://doi.org/10.1037/a0026969

Giedd, J. N., Raznahan, A., Alexander-Bloch, A., Schmitt, E., Gogtay, N., \& Rapoport, J. L. (2015, January 8). Child psychiatry branch of the national institute of mental health longitudinal structural magnetic resonance imaging study of human brain development. Neuropsychopharmacology. Nature Publishing Group.

https://doi.org/10.1038/npp.2014.236

Ginsburg, K. R. (2007). The importance of play in promoting healthy child development and maintaining strong parent-child bonds. Clinical report. Pediatrics, 119(1), 182-191. https://doi.org/10.1111/j.1365-2214.2007.00799_8.x

Gleich, T., Lorenz, R. C., Gallinat, J., \& Kühn, S. (2017). Functional changes in the reward circuit in response to gaming-related cues after training with a commercial video game. NeuroImage, 152, 467-475. https://doi.org/10.1016/j.neuroimage.2017.03.032

Golland, Y., Arzouan, Y., \& Levit-Binnun, N. (2015). The mere Co-presence:

Synchronization of autonomic signals and emotional responses across Co-present individuals not engaged in direct interaction. PLOS ONE, 10(5). https://doi.org/10.1371/journal.pone.0125804

González, V. M., \& Mark, G. (2004). \&quot;Constant, constant, multi-tasking craziness\&quot; : managing multiple working spheres. In Proceedings of the 2004 conference on Human factors in computing systems - CHI '04 (pp. 113-120). https://doi.org/10.1145/985692.985707 
Graves, L. E. F., Ridgers, N. D., Atkinson, G., \& Stratton, G. (2010). The effect of active video gaming on children's physical activity, behavior preferences and body composition. Pediatric Exercise Science, 22(4), 535-546. https://doi.org/10.1123/pes.22.4.535

Graybill, D., Strawniak, M., Hunter, T., \& O’Leary, M. (1987). Effects of playing versus observing violent versus nonviolent video games on children's aggression. Psychology: A Journal of Human Behavior.

Green, C. S., \& Bavelier, D. (2003). Action video game modifies visual selective attention. Nature, 423(6939), 534-537. https://doi.org/10.1038/nature01647

Green, C. S., \& Bavelier, D. (2006a). Effect of action video games on the spatial distribution of visuospatial attention. Journal of Experimental Psychology: Human Perception and Performance, 32(6), 1465-1478. https://doi.org/10.1037/0096-1523.32.6.1465

Green, C. S., \& Bavelier, D. (2006b). Enumeration versus multiple object tracking: the case of action video game players. Cognition, 101(1), 217-245. https://doi.org/10.1016/j.cognition.2005.10.004

Green, C. S., \& Bavelier, D. (2007). Action-video-game experience alters the spatial resolution of vision: Research article. Psychological Science, 18(1), 88-94. https://doi.org/10.1111/j.1467-9280.2007.01853.x

Green, C. S., \& Bavelier, D. (2012). Learning, attentional control, and action video games. Current Biology, 22(6), R197-R206. https://doi.org/10.1016/j.cub.2012.02.012

Green, C. S., Pouget, A., \& Bavelier, D. (2010). Improved probabilistic inference as a general learning mechanism with action video games. Current Biology, 20(17), 1573-1579. https://doi.org/10.1016/j.cub.2010.07.040

Green, C. S., \& Seitz, A. R. (2015). The Impacts of Video Games on Cognition (and How the Government Can Guide the Industry). Policy Insights from the Behavioral and Brain 
Sciences, 2(1), 101-110. https://doi.org/10.1177/2372732215601121

Green, C. S., Sugarman, M. A., Medford, K., Klobusicky, E., \& Bavelier, D. (2012). The effect of action video game experience on task-switching. Computers in Human Behavior, 28(3), 984-994. https://doi.org/10.1016/j.chb.2011.12.020

Greenfield, P. M., Brannon, C., \& Lohr, D. (1994). Two-dimensional representation of movement through three-dimensional space: The role of video game expertise. Journal of Applied Developmental Psychology, 15(1), 87-103. https://doi.org/10.1016/01933973(94)90007-8

Greenfield, P. M., Camaioni, L., Ercolani, P., Weiss, L., Lauber, B. A., \& Perucchini, P. (1994). Cognitive socialization by computer games in two cultures: Inductive discovery or mastery of an iconic code? Journal of Applied Developmental Psychology, 15(1), 5985. https://doi.org/10.1016/0193-3973(94)90006-X

Greenfield, P. M., DeWinstanley, P., Kilpatrick, H., \& Kaye, D. (1994). Action video games and informal education: Effects on strategies for dividing visual attention. Journal of Applied Developmental Psychology, 15(1), 105-123. https://doi.org/10.1016/01933973(94)90008-6

Greenhalgh, T., \& Peacock, R. (2005, November 5). Effectiveness and efficiency of search methods in systematic reviews of complex evidence: Audit of primary sources. British Medical Journal. British Medical Journal Publishing Group. https://doi.org/10.1136/bmj.38636.593461.68

Greitemeyer, T. (2013). Playing video games cooperatively increases empathic concern. Social Psychology, 44(6), 408-413. https://doi.org/10.1027/1864-9335/a000154

Greitemeyer, T. (2014). Intense acts of violence during video game play make daily life aggression appear innocuous: A new mechanism why violent video games increase aggression. Journal of Experimental Social Psychology, 50(1), 52-56. 
https://doi.org/10.1016/j.jesp.2013.09.004

Greitemeyer, T., Agthe, M., Turner, R., \& Gschwendtner, C. (2012). Acting prosocially reduces retaliation: Effects of prosocial video games on aggressive behavior. European Journal of Social Psychology, 42(2), 235-242. https://doi.org/10.1002/ejsp.1837

Greitemeyer, T., \& McLatchie, N. (2011). Denying humanness to others: A newly discovered mechanism by which violent video games increase aggressive behavior. Psychological Science, 22(5), 659-665. https://doi.org/10.1177/0956797611403320

Greitemeyer, T., \& Mügge, D. O. (2014). Video games do affect social outcomes: a metaanalytic review of the effects of violent and prosocial video game play. Personality \& Social Psychology Bulletin, 40(5), 578-589. https://doi.org/10.1177/0146167213520459

Greitemeyer, T., \& Osswald, S. (2009). Prosocial video games reduce aggressive cognitions. Journal of Experimental Social Psychology, 45(4), 896-900. https://doi.org/10.1016/j.jesp.2009.04.005

Greitemeyer, T., \& Osswald, S. (2010). Effects of Prosocial Video Games on Prosocial Behavior. Journal of Personality and Social Psychology, 98(2), 211-221. https://doi.org/10.1037/a0016997

Greitemeyer, T., \& Osswald, S. (2011). Playing prosocial video games increases the accessibility of prosocial thoughts. Journal of Social Psychology, 151(2), 121-128. https://doi.org/10.1080/00224540903365588

Greitemeyer, T., Osswald, S., \& Brauer, M. (2010). Playing Prosocial Video Games Increases Empathy and Decreases Schadenfreude. Emotion, 10(6), 796-802. https://doi.org/10.1037/a0020194

Guertler, D., Rumpf, H. J., Bischof, A., Kastirke, N., Petersen, K. U., John, U., \& Meyer, C. (2014). Assessment of problematic internet use by the compulsive internet use scale and the internet addiction test: A sample of problematic and pathological gamblers. 
European Addiction Research, 20(2), 75-81. https://doi.org/10.1159/000355076

Haier, R. J., Karama, S., Leyba, L., \& Jung, R. E. (2009). MRI assessment of cortical thickness and functional activity changes in adolescent girls following three months of practice on a visual-spatial task. BMC Research Notes, 2. https://doi.org/10.1186/17560500-2-174

Hari, R., Himberg, T., Nummenmaa, L., Hämäläinen, M., \& Parkkonen, L. (2013). Synchrony of brains and bodies during implicit interpersonal interaction. Trends in Cognitive Sciences. https://doi.org/10.1016/j.tics.2013.01.003

Harris, J. L., Bargh, J. A., \& Brownell, K. D. (2009). Priming effects of television food advertising on eating behavior. Health Psychology : Official Journal of the Division of Health Psychology, American Psychological Association, 28(4), 404-413. https://doi.org/10.1037/a0014399

Hasan, Y., Bègue, L., \& Bushman, B. J. (2013). Violent Video Games Stress People Out and Make Them More Aggressive. Aggressive Behavior, 39(1), 64-70. https://doi.org/10.1002/ab.21454

Helliwell, J. F., \& Putnam, R. D. (2004). The social context of well-being. Philosophical Transactions of the Royal Society of London. Series B, Biological Sciences, 359(1449), 1435-1446. https://doi.org/10.1098/rstb.2004.1522

Hensch, T. K., \& Bilimoria, P. M. (2012). Re-opening Windows: Manipulating Critical Periods for Brain Development. Cerebrum : The Dana Forum on Brain Science, 2012(August), 11.

Hicks, D. J. (1965). Imitation and retention of film-mediated aggressive peer and adult models. Journal of Personality and Social Psychology, 2(1), 97-100. https://doi.org/10.1037/h0022075

Higgs, S., \& Woodward, M. (2009). Television watching during lunch increases afternoon 
snack intake of young women. Appetite, 52(1), 39-43.

https://doi.org/10.1016/j.appet.2008.07.007

Higuchi, S., Motohashi, Y., Liu, Y., \& Maeda, A. (2005). Effects of playing a computer game using a bright display on presleep physiological variables, sleep latency, slow wave sleep and REM sleep. Journal of Sleep Research, 14(3), 267-273. https://doi.org/10.1111/j.1365-2869.2005.00463.x

Hofferth, S. L. (2010). Home media and children's achievement and behavior. Child Development, 81(5), 1598-1619. https://doi.org/10.1111/j.1467-8624.2010.01494.x

Hofferth, S. L., \& Moon, U. J. (2012). Electronic Play, Study, Communication, and Adolescent Achievement, 2003-2008. Journal of Research on Adolescence, 22(2), 215224. https://doi.org/10.1111/j.1532-7795.2011.00770.x

Hollingdale, J., \& Greitemeyer, T. (2013). The changing face of aggression: The effect of personalized avatars in a violent video game on levels of aggressive behavior. Journal of Applied Social Psychology, 43(9), 1862-1868. https://doi.org/10.1111/jasp.12148

Hollingdale, J., \& Greitemeyer, T. (2014). The effect of online violent video games on levels of aggression. PLoS ONE, 9(11). https://doi.org/10.1371/journal.pone.0111790

Holz, C., Bentley, F., Church, K., \& Patel, M. (2015). "I'm just on my phone and they're watching TV": Quantifying mobile device use while watching television. In $T V X$ '15 Proceedings of the ACM International Conference on Interactive Experiences for TV and Online Video (pp. 93-102). https://doi.org/10.1145/2745197.2745210

Houghton, S., Hunter, S. C., Rosenberg, M., Wood, L., Zadow, C., Martin, K., \& Shilton, T. (2015). Virtually impossible: Limiting Australian children and adolescents daily screen based media use. BMC Public Health, 15(1), 5. https://doi.org/10.1186/1471-2458-15-5 Hysing, M., Pallesen, S., Stormark, K. M., Jakobsen, R., Lundervold, A. J., \& Sivertsen, B. (2015). Sleep and use of electronic devices in adolescence: Results from a large 
population-based study. BMJ Open, 5(1), e006748. https://doi.org/10.1136/bmjopen2014-006748

Irwin, A. R., \& Gross, A. M. (1995). Cognitive tempo, violent video games, and aggressive behavior in young boys. Journal of Family Violence, 10(3), 337-350. https://doi.org/10.1007/BF02110997

Janssen, I., \& Leblanc, A. G. (2010). Systematic review of the health benefits of physical activity and fitness in school-aged children and youth. The International Journal of Behavioral Nutrition and Physical Activity, 7, 40. https://doi.org/10.1186/1479-5868-740

Johnson, S., \& Wolke, D. (2013, April 1). Behavioural outcomes and psychopathology during adolescence. Early Human Development. Elsevier. https://doi.org/10.1016/j.earlhumdev.2013.01.014

Kabali, H. K., Irigoyen, M. M., Nunez-Davis, R., Budacki, J. G., Mohanty, S. H., Leister, K. P., \& Bonner, R. L. (2015). Exposure and Use of Mobile Media Devices by Young Children. Pediatrics, 136(6), 1044-1050. https://doi.org/10.1542/peds.2015-2151

Keng, S.-L., Smoski, M. J., \& Robins, C. J. (2011). Effects of mindfulness on psychological health: a review of empirical studies. Clinical Psychology Review, 31(6), 1041-1056. https://doi.org/10.1016/j.cpr.2011.04.006

Kerimoglu, B., Neuman, A., Paul, J., Stefanov, D. G., \& Twersky, R. (2013). Anesthesia induction using video glasses as a distraction tool for the management of preoperative anxiety in children. Anesthesia and Analgesia, 117(6), 1373-1379. https://doi.org/10.1213/ANE.0b013e3182a8c18f

Kim, H., Jung, S. M., Yu, H., \& Park, S. J. (2015). Video Distraction and Parental Presence for the Management of Preoperative Anxiety and Postoperative Behavioral Disturbance in Children: A Randomized Controlled Trial. Anesthesia and Analgesia, 121(3), 778- 
784. https://doi.org/10.1213/ANE.0000000000000839

Kirsh, S. J. (1998). Seeing the world through mortal kombat-colored glasses: Violent video games and the development of a short-term hostile attribution bias. Childhood, 5(2), 177-184. https://doi.org/10.1177/0907568298005002005

Kirsh, S. J., \& Mounts, J. R. W. (2007). Violent video game play impacts facial emotion recognition. Aggressive Behavior, 33(4), 353-358. https://doi.org/10.1002/ab.20191

Kirsh, S. J., Olczak, P. V., \& Mounts, J. R. W. (2005). Violent video games induce an affect processing bias. Media Psychology, 7(3), 239-250. https://doi.org/10.1207/S1532785XMEP0703_1

Kohn Friedrich, L., \& Huston Stein, A. (1973). Aggressive and Prosocial Television Programs and the Natural Behavior of Preschool Children. Source: Monographs of the Society for Research in Child Development, 38(4), 1-64.

https://doi.org/10.2307/1165725

Konijn, E. A., Bijvank, M. N., \& Bushman, B. J. (2007). I Wish I Were a Warrior: The Role of Wishful Identification in the Effects of Violent Video Games on Aggression in Adolescent Boys. Developmental Psychology, 43(4), 1038-1044. https://doi.org/10.1037/0012-1649.43.4.1038

Kühn, S., Gleich, T., Lorenz, R. C., Lindenberger, U., \& Gallinat, J. (2014). Playing super mario induces structural brain plasticity: Gray matter changes resulting from training with a commercial video game. Molecular Psychiatry, 19(2), 265-271. https://doi.org/10.1038/mp.2013.120

Laposky, A. D., Van Cauter, E., \& Diez-Roux, A. V. (2016). Reducing health disparities: The role of sleep deficiency and sleep disorders. Sleep Medicine, 18, 3-6. https://doi.org/10.1016/j.sleep.2015.01.007

LeBlanc, A. G., Katzmarzyk, P. T., Barreira, T. V., Broyles, S. T., Chaput, J. P., Church, T. 
S., ... Wiltz, D. (2015). Correlates of total sedentary time and screen time in 9-11 yearold children around the world: The international study of childhood obesity, lifestyle and the environment. PLoS ONE, 10(6), e0129622. https://doi.org/10.1371/journal.pone.0129622

Lee, H., Voss, M. W., Prakash, R. S., Boot, W. R., Vo, L. T. K., Basak, C., ... Kramer, A. F. (2012). Videogame training strategy-induced change in brain function during a complex visuomotor task. Behavioural Brain Research, 232(2), 348-357. https://doi.org/10.1016/j.bbr.2012.03.043

Leong, V., Byrne, E., Clackson, K., Georgieva, S., Lam, S., \& Wass, S. (2017). Speaker gaze increases information coupling between infant and adult brains. Proceedings of the National Academy of Sciences, 201702493. https://doi.org/10.1073/pnas.1702493114

Li, F., Nigg, C., McGlone, K., Fialkowski, M., Wilkens, L., Paulino, Y., ... Novotny, R. (2015). Young children's screen time and obesity in the U.S. affiliated pacific: The children's healthy living program. FASEB Journal, 29(1 Meeting Abstracts).

Li, L., Chen, R., \& Chen, J. (2016). Playing Action Video Games Improves Visuomotor Control. Psychological Science, 27(8), 1092-1108. https://doi.org/10.1177/0956797616650300

Li, R., Polat, U., Makous, W., \& Bavelier, D. (2009). Enhancing the contrast sensitivity function through action video game training. Nature Neuroscience, 12(5), 549-551. https://doi.org/10.1038/nn.2296

Li, R., Polat, U., Scalzo, F., \& Bavelier, D. (2010). Reducing backward masking through action game training. Journal of Vision, 10(14), 33-33. https://doi.org/10.1167/10.14.33

Liebert, R. M., \& Baron, R. A. (1972). Some immediate effects of televised violence on children's behavior. Developmental Psychology, 6(3), 469-475. https://doi.org/10.1037/h0032584 
Lucas, K., \& Sherry, J. L. (2004). Sex differences in video game play: A communicationbased explanation. Communication Research, 31(5), 499-523.

https://doi.org/10.1177/0093650204267930

Luyster, F. S., Strollo, P. J., Zee, P. C., \& Walsh, J. K. (2012). Sleep: A Health Imperative. Sleep, 35(6), 727-734. https://doi.org/10.5665/sleep.1846

Lyons, E. J., Tate, D. F., Komoski, S. E., Carr, P. M., \& Ward, D. S. (2012). Novel approaches to obesity prevention: Effects of game enjoyment and game type on energy expenditure in active video games. In Journal of Diabetes Science and Technology (Vol. 6, pp. 839-848). https://doi.org/10.1177/193229681200600415

Maillot, P., Perrot, A., \& Hartley, A. (2012). Effects of interactive physical-activity videogame training on physical and cognitive function in older adults. Psychology and Aging, 27(3), 589-600. https://doi.org/10.1037/a0026268

Mark, G., Gonzalez, V. M., \& Harris, J. (2005). No Task Left Behind? Examining the Nature of Fragmented Work. CHI 2005 Proceedings of the SIGCHI Conference on Human Factors in Computing Systems, 321-330. https://doi.org/doi: 10.1145/1054972.1055017

Mark, G., Wang, Y., \& Niiya, M. (2014). Stress and multitasking in everyday college life: An empirical study of online activity. In Proceedings of the 32nd annual ACM conference on Human factors in computing systems - CHI '14 (pp. 41-50). https://doi.org/10.1145/2556288.2557361

Martin, C. K., Coulon, S. M., Markward, N., Greenway, F. L., \& Anton, S. D. (2009). Association between energy intake and viewing television, distractibility, and memory for advertisements. American Journal of Clinical Nutrition, 89(1), 37-44. https://doi.org/10.3945/ajen.2008.26310

Martínez, K., Solana, A. B., Burgaleta, M., Hernández-Tamames, J. A., Álvarez-Linera, J., Román, F. J., ... Colom, R. (2013). Changes in resting-state functionally connected 
parietofrontal networks after videogame practice. Human Brain Mapping, 34(12), 31433157. https://doi.org/10.1002/hbm.22129

Mastro, D., Behm-Morawitz, E., \& Kopacz, M. A. (2008). Exposure to television portrayals of Latinos: The implications of aversive racism and social identity theory. Human Communication Research, 34(1), 1-27. https://doi.org/10.1111/j.14682958.2007.00311.x

Mastro, D., Lapinski, M. K., Kopacz, M. A., \& Behm-Morawitz, E. (2009). The influence of exposure to depictions of race and crime in TV news on viewer's social judgments. Journal of Broadcasting and Electronic Media, 53(4), 615-635. https://doi.org/10.1080/08838150903310534

McClurg, P. A., \& Chaille, C. (1987). Computer games: Environments for Developing Spatial Cognition? Journal of Educational Computing Research, 3(1), 95-112. https://doi.org/10.1017/CBO9781107415324.004

McEwen, B. S. (2012). Brain on stress: How the social environment gets under the skin. Proceedings of the National Academy of Sciences, 109(Supplement_2), 17180-17185. https://doi.org/10.1073/pnas.1121254109

Mifflin, K. A., Hackmann, T., \& Chorney, J. M. L. (2012). Streamed video clips to reduce anxiety in children during inhaled induction of anesthesia. Anesthesia and Analgesia, 115(5), 1162-1167. https://doi.org/10.1213/ANE.0b013e31824d5224

Milburn, M. a, Mather, R., \& Conrad, S. D. (2000). The Effects of Viewing R-rated Movie Scenes That Objectify Women on Perceptions of Date Rape. Sex Roles, 43, 645-664. https://doi.org/0360-0025/00/1100-0645\$18.00/0

Milteer, R. M., Ginsburg, K. R., \& Mulligan, D. A. (2012). The Importance of Play in Promoting Healthy Child Development and Maintaining Strong Parent-Child Bond: Focus on Children in Poverty. PEDIATRICS, 129(1), e204-e213. 
https://doi.org/10.1542/peds.2011-2953

Mun, S., Kim, E. S., \& Park, M. C. (2014). Effect of mental fatigue caused by mobile 3D viewing on selective attention: An ERP study. International Journal of Psychophysiology, 94(3), 373-381. https://doi.org/10.1016/j.ijpsycho.2014.08.1389

Nelson, T. M., \& Carlson, D. R. (1985). Determining Factors in Choice of Arcade Games and their Consequences upon Young Male Players. Journal of Applied Social Psychology, 15(2), 124-139. https://doi.org/10.1111/j.1559-1816.1985.tb02339.x

Nikolaidis, A., Voss, M. W., Lee, H., Vo, L. T. K., \& Kramer, A. F. (2014). Parietal plasticity after training with a complex video game is associated with individual differences in improvements in an untrained working memory task. Frontiers in Human Neuroscience, 8 . https://doi.org/10.3389/fnhum.2014.00169

Ogletree, S. M., \& Drake, R. (2007). College students' video game participation and perceptions: Gender differences and implications. Sex Roles, 56(7-8), 537-542. https://doi.org/10.1007/s11199-007-9193-5

Okagaki, L., \& Frensch, P. A. (1994). Effects of video game playing on measures of spatial performance: Gender effects in late adolescence. Journal of Applied Developmental Psychology, 15(1), 33-58. https://doi.org/10.1016/0193-3973(94)90005-1

Oldham-Cooper, R. E., Hardman, C. A., Nicoll, C. E., Rogers, P. J., \& Brunstrom, J. M. (2011). Playing a computer game during lunch affects fullness, memory for lunch, and later snack intake. American Journal of Clinical Nutrition, 93(2), 308-313. https://doi.org/10.3945/ajen.110.004580

Orosy-Fildes, C., \& Allan, R. W. (1989). Psychology of computer use: XII. Videogame play: Human reaction time to visual stimuli. Perceptual and Motor Skills. Vol 69(1), 243-247. https://doi.org/10.2466/pms.1989.69.1.243

Patel, A., Schieble, T., Davidson, M., Tran, M. C. J., Schoenberg, C., Delphin, E., \& Bennett, 
H. (2006). Distraction with a hand-held video game reduces pediatric preoperative anxiety. Paediatric Anaesthesia, 16(10), 1019-1027. https://doi.org/10.1111/j.14609592.2006.01914.x

Pea, R., Nass, C., Meheula, L., Rance, M., Kumar, A., Bamford, H., ... Yang, S. (2012). Media use, face-to-face communication, media multitasking, and social well-being among 8-to 12-year-old girls. Developmental Psychology, 48(2), 327. https://doi.org/10.1037/a0027030

Pena, J., Hancock, J. T., \& Merola, N. A. (2009). The priming effects of avatars in virtual settings. Communication Research, 36(6), 838-856.

https://doi.org/10.1177/0093650209346802

Penedo, F. J., \& Dahn, J. R. (2005). Exercise and well-being: A review of mental and physical health benefits associated with physical activity. Current Opinion in Psychiatry. https://doi.org/10.1097/00001504-200503000-00013

Peng, W., Crouse, J. C., \& Lin, J.-H. (2012). Using Active Video Games for Physical Activity Promotion: A Systematic Review of the Current State of Research. Health Education \& Behavior: The Official Publication of the Society for Public Health Education, 40(2), 171-192. https://doi.org/10.1177/1090198112444956

Pépin, M., \& Dorval, M. (1986). Effect of Playing a Video Game on Adults' and Adolescents Spatial Visualization. In the Annual Meeting of the American Educational Research Association.

Petersen, S. ., \& Posner, M. (2012). The attention system of the human brain: 20 years after. Annual Review of Neuroscience, 21(35), 73-89. https://doi.org/10.1146/annurev-neuro062111-150525.The

Phillips, C. A., Rolls, S., Rouse, A., \& Griffiths, M. D. (1995). Home video game playing in schoolchildren: A study of incidence and patterns of play. Journal of Adolescence, 
18(6), 687-691. https://doi.org/10.1006/jado.1995.1049

Piehler, C. (2015). Sharing Screens All Over the Classroom. T H E Journal, $42(3), 27$.

Retrieved from

http://ezproxy.georgetowncollege.edu:2048/login?URL=http://search.ebscohost.com/log in. aspx $?$ direct $=$ true $\& d b=a 9 h \& A N=102117779$

Polman, H., De Castro, B. O., \& Van Aken, M. A. G. (2008). Experimental study of the differential effects of playing versus watching violent video games on children's aggressive behavior. Aggressive Behavior, 34(3), 256-264. https://doi.org/10.1002/ab.20245

Ralph, B. C. W., Thomson, D. R., Cheyne, J. A., \& Smilek, D. (2014). Media multitasking and failures of attention in everyday life. Psychological Research, 78(5), 661-669. https://doi.org/10.1007/s00426-013-0523-7

Raznahan, A., Greenstein, D., Lee, N. R., Clasen, L. S., \& Giedd, J. N. (2012). Prenatal growth in humans and postnatal brain maturation into late adolescence. Proceedings of the National Academy of Sciences, 109(28), 11366-11371.

https://doi.org/10.1073/pnas.1203350109

Rideout, V. J., Foehr, U. G., \& Roberts, D. F. (2010). Generation M2: Media in the Lives of 8 to 18 Year-Olds. The Henry J. Kaiser Family Foundation, 1-79. https://doi.org/P0$446179799-1366925520306$

Robinson, T. N. (1999). Reducing Children's Television Viewing to Prevent Obesity A Randomized Controlled Trial. JAMA, 282(16), 1561. https://doi.org/10.1542/peds.20060732

Robinson, T. N., Wilde, M. L., Navracruz, L. C., Haydel, K. F., \& Varady, A. (2001). Effects of reducing children's television and video game use on aggressive behavior: a randomized controlled trial. Archives of Pediatrics \& Adolescent Medicine, 155(1), 17- 
23.

Roth, T. L., \& Sweatt, J. D. (2011, April 1). Annual research review: Epigenetic mechanisms and environmental shaping of the brain during sensitive periods of development. Journal of Child Psychology and Psychiatry and Allied Disciplines. Blackwell Publishing Ltd. https://doi.org/10.1111/j.1469-7610.2010.02282.x

Sanchez, C. A. (2012). Enhancing visuospatial performance through video game training to increase learning in visuospatial science domains. Psychonomic Bulletin and Review, 19(1), 58-65. https://doi.org/10.3758/s13423-011-0177-7

Scharrer, E. (2005). Hypermasculinity, aggression, and television violence: An experiment. Media Psychology, 7(4), 353-376. https://doi.org/10.1207/S1532785XMEP0704_3

Schmierbach, M. (2010). "killing spree": Exploring the connection between competitive game play and aggressive cognition. Communication Research, 37(2), 256-274. https://doi.org/10.1177/0093650209356394

Schutte, N. S., Malouff, J. M., Post-Gorden, J. C., \& Rodasta, A. L. (1988). Effects of Playing Videogames on Children's Aggressive and Other Behaviors. Journal of Applied Social Psychology, 18(5), 454-460. https://doi.org/10.1111/j.1559-1816.1988.tb00028.x

Scott, D. (1995). The effect of video games on feelings of aggression. Journal of Psychology: Interdisciplinary and Applied, 129(2), 121-132.

https://doi.org/10.1080/00223980.1995.9914952

Sheese, B. E., \& Graziano, W. G. (2005). Deciding to defect: The effects of video-game violence on cooperative behavior. Psychological Science, 16(5), 354-357. https://doi.org/10.1111/j.0956-7976.2005.01539.x

Shih, S. I. (2013). A Null Relationship between Media Multitasking and Well-Being. PLoS ONE, 8(5). https://doi.org/10.1371/journal.pone.0064508

Sigmund, E., Sigmundová, D., Badura, P., Kalman, M., Hamrik, Z., \& Pavelka, J. (2015). 
Temporal trends in overweight and obesity, physical activity and screen time among Czech adolescents from 2002 to 2014: A national health behaviour in school-aged children study. International Journal of Environmental Research and Public Health, 12(9), 11848-11868. https://doi.org/10.3390/ijerph120911848

Silvern, S. B., \& Williamson, P. A. (1987). The effects of video game play on young children's aggression, fantasy, and prosocial behavior. Journal of Applied Developmental Psychology, 8(4), 453-462. https://doi.org/10.1016/01933973(87)90033-5

Sims, V. K., \& Mayer, R. E. (2002). Domain specificity of spatial expertise: The case of video game players. Applied Cognitive Psychology, 16(1), 97-115. https://doi.org/10.1002/acp.759

Slagter, H. . A., Davidson, R. J., \& Lutz, A. (2011). Mental training as a tool in the neuroscientific study of brain and cognitive plasticity. Frontiers in Human Neuroscience, 5, 17. https://doi.org/10.3389/fnhum.2011.00017

Slagter, H. A., Lutz, A., Greischar, L. L., Francis, A. D., Nieuwenhuis, S., Davis, J. M., \& Davidson, R. J. (2007). Mental training affects distribution of limited brain resources. PLoS Biology, 5(6), 1228-1235. https://doi.org/10.1371/journal.pbio.0050138

Somerville, L. H., Jones, R. M., \& Casey, B. J. (2010, February 1). A time of change: Behavioral and neural correlates of adolescent sensitivity to appetitive and aversive environmental cues. Brain and Cognition. Academic Press. https://doi.org/10.1016/j.bandc.2009.07.003

Stempel, G. H., Hargrove, T., \& Bernt, J. P. (2000). Relation of growth of use of the internet to changes in media use from 1995 to 1999. Journalism and Mass Communication Quaterly. https://doi.org/10.1177/107769900007700106

Stern, Y., Blumen, H. M., Rich, L. W., Richards, A., Herzberg, G., \& Gopher, D. (2011). 
Space Fortress game training and executive control in older adults: a pilot intervention. Neuropsychology, Development, and Cognition. Section B, Aging, Neuropsychology and Cognition, 18(6), 653-677. https://doi.org/10.1080/13825585.2011.613450

Steuer, F. B., Applefield, J. M., \& Smith, R. (1971). Televised aggression and the interpersonal aggression of preschool children. Journal of Experimental Child Psychology, 11(3), 442-447. https://doi.org/10.1016/0022-0965(71)90048-8

Subrahmanyam, K., \& Greenfield, P. M. (1994). Effect of video game practice on spatial skills in girls and boys. Journal of Applied Developmental Psychology, 15(1), 13-32. https://doi.org/10.1016/0193-3973(94)90004-3

Tamborini, R., Eastin, M., Lachlan, K., Skalski, P., Fediuk, T., \& Brady, R. (2001). Hostile Thoughts, Presence and Violent Virtual Video Games. In 51st annual convention of the International Communication Association, Washington, DC.

Tamborini, R., Eastin, M. S., Skalski, P., Lachlan, K., Fediuk, T. a, \& Brady, R. (2004). Violent Virtual Video Games and Hostile Thoughts. Journal of Broadcasting and Electronic Media, 48(3), 335-357.

Tandon, P., Grow, H. M., Couch, S., Glanz, K., Sallis, J. F., Frank, L. D., \& Saelens, B. E. (2014). Physical and social home environment in relation to children's overall and home-based physical activity and sedentary time. Preventive Medicine, 66, 39-44. https://doi.org/10.1016/j.ypmed.2014.05.019

Tear, M. J., \& Nielsen, M. (2013). Failure to Demonstrate That Playing Violent Video Games Diminishes Prosocial Behavior. PLoS ONE, 8(7). https://doi.org/10.1371/journal.pone.0068382

Teng, S. K. Z., Chong, G. Y. M., Siew, A. S. C., \& Skoric, M. M. (2011). Grand Theft Auto IV Comes to Singapore: Effects of Repeated Exposure to Violent Video Games on Aggression. Cyberpsychology, Behavior, and Social Networking, 14(10), 597-602. 
https://doi.org/10.1089/cyber.2010.0115

Tondeur, J., De Bruyne, E., Van Den Driessche, M., McKenney, S., \& Zandvliet, D. (2015).

The physical placement of classroom technology and its influences on educational practices. Cambridge Journal of Education, 45(4), 537-556.

https://doi.org/10.1080/0305764X.2014.998624

Tsitsika, A. K., Andrie, E. K., Psaltopoulou, T., Tzavara, C. K., Sergentanis, T. N., NtanasisStathopoulos, I., ... Tsolia, M. (2016). Association between problematic internet use, socio-demographic variables and obesity among European adolescents. The European Journal of Public Health, 26(4), ckw028. https://doi.org/10.1093/eurpub/ckw028

Twenge, J. M., Krizan, Z., \& Hisler, G. (2017). Decreases in self-reported sleep duration among U.S. adolescents 2009-2015 and links to new media screen time. Sleep Medicine, 39, 47-53. https://doi.org/10.1016/j.sleep.2017.08.013

Ussher, M. H., Owen, C. G., Cook, D. G., \& Whincup, P. H. (2007). The relationship between physical activity, sedentary behaviour and psychological wellbeing among adolescents. Social Psychiatry and Psychiatric Epidemiology, 42(10), 851-856. https://doi.org/10.1007/s00127-007-0232-x

Valadez, J. J., \& Ferguson, C. J. (2012). Just a game after all: Violent video game exposure and time spent playing effects on hostile feelings, depression, and visuospatial cognition. Computers in Human Behavior, 28(2), 608-616. https://doi.org/10.1016/j.chb.2011.11.006

Van Der Aa, N., Overbeek, G., Engels, R. C. M. E., Scholte, R. H. J., Meerkerk, G. J., \& Van Den Eijnden, R. J. J. M. (2009). Daily and compulsive internet use and well-being in adolescence: A diathesis-stress model based on big five personality traits. Journal of Youth and Adolescence, 38(6), 765-776. https://doi.org/10.1007/s10964-008-9298-3

Van Der Lely, S., Frey, S., Garbazza, C., Wirz-Justice, A., Jenni, O. G., Steiner, R., ... 
Schmidt, C. (2015). Blue blocker glasses as a countermeasure for alerting effects of evening light-emitting diode screen exposure in male teenagers. Journal of Adolescent Health, 56(1), 113-119. https://doi.org/10.1016/j.jadohealth.2014.08.002

Van Der Schuur, W. A., Baumgartner, S. E., Sumter, S. R., \& Valkenburg, P. M. (2015). The consequences of media multitasking for youth: A review. Computers in Human Behavior, 53, 204-215. https://doi.org/10.1016/j.chb.2015.06.035

van Ravenzwaaij, D., Boekel, W., Forstmann, B. U., Ratcliff, R., \& Wagenmakers, E. J. (2014). Action video games do not improve the speed of information processing in simple perceptual tasks. Journal of Experimental Psychology: General, 143(5), 17941805. https://doi.org/10.1037/a0036923

Velez, J. A., Mahood, C., Ewoldsen, D. R., \& Moyer-Gusé, E. (2014). Ingroup Versus Outgroup Conflict in the Context of Violent Video Game Play: The Effect of Cooperation on Increased Helping and Decreased Aggression. Communication Research, 41(5), 607-626. https://doi.org/10.1177/0093650212456202

Voss, M. W., Prakash, R. S., Erickson, K. I., Boot, W. R., Basak, C., Neider, M. B., ... Kramer, A. F. (2012). Effects of training strategies implemented in a complex videogame on functional connectivity of attentional networks. NeuroImage, 59(1), 138148. https://doi.org/10.1016/j.neuroimage.2011.03.052

Walters, R. H., \& Willows, D. C. (1968). Imitative Behavior of Disturbed and Nondisturbed Children Following Exposure to Aggressive and Nonaggressive Models. Child Development, 39(1), 79. https://doi.org/10.2307/1127360

Ward, A. F., Duke, K., Gneezy, A., \& Bos, M. W. (2017). Brain Drain: The Mere Presence of One's Own Smartphone Reduces Available Cognitive Capacity. Journal of the Association for Consumer Research, 2(2), 140-154. https://doi.org/10.1086/691462

Weinstein, A., Yaacov, Y., Manning, M., Danon, P., \& Weizman, A. (2015). Internet 
Addiction and Attention Deficit Hyperactivity Disorder Among Schoolchildren. The Israel Medical Association Journal : IMAJ, 17(12), 731-734.

Weis, R., \& Cerankosky, B. C. (2010). Effects of video-game ownership on young boys' academic and behavioral functioning: A randomized, controlled study. Psychological Science, 21(4), 463-470. https://doi.org/10.1177/0956797610362670

Wen, C. P., Wai, J. P. M., Tsai, M. K., Yang, Y. C., Cheng, T. Y. D., Lee, M. C., ... Wu, X. (2011). Minimum amount of physical activity for reduced mortality and extended life expectancy: A prospective cohort study. The Lancet, 378(9798), 1244-1253. https://doi.org/10.1016/S0140-6736(11)60749-6

West, K. E., Jablonski, M. R., Warfield, B., Cecil, K. S., James, M., Ayers, M. A., ... Brainard, G. C. (2011). Blue light from light-emitting diodes elicits a dose-dependent suppression of melatonin in humans. Journal of Applied Physiology, 110(3), 619-626. https://doi.org/10.1152/japplphysiol.01413.2009

Williams, D., \& Skoric, M. (2005). Internet fantasy violence: A test of aggression in an online game. Communication Monographs, 72(2), 217-233. https://doi.org/10.1080/03637750500111781

Williams, R. B., \& Clippinger, C. A. (2002). Aggression, competition and computer games: Computer and human opponents. Computers in Human Behavior, 18(5), 495-506. https://doi.org/10.1016/S0747-5632(02)00009-2

Winkel, M., Novak, D. M., \& Hopson, H. (1987). Personality factors, subject gender, and the effects of aggressive video games on aggression in adolescents. Journal of Research in Personality, 21(2), 211-223. https://doi.org/10.1016/0092-6566(87)90008-0

Wood, B., Rea, M. S., Plitnick, B., \& Figueiro, M. G. (2013). Light level and duration of exposure determine the impact of self-luminous tablets on melatonin suppression. Applied Ergonomics, 44(2), 237-240. https://doi.org/10.1016/j.apergo.2012.07.008 
Wu, S., Cheng, C. K., Feng, J., D’Angelo, L., Alain, C., \& Spence, I. (2012). Playing a Firstperson Shooter Video Game Induces Neuroplastic Change. Journal of Cognitive Neuroscience, 24(6), 1286-1293. https://doi.org/10.1162/jocn_a_00192

Wu, S., \& Spence, I. (2013). Playing shooter and driving videogames improves top-down guidance in visual search. Attention, Perception, and Psychophysics, 75(4), 673-686. https://doi.org/10.3758/s13414-013-0440-2

Yang, G. S., Gibson, B., Lueke, A. K., Huesmann, L. R., \& Bushman, B. J. (2014). Effects of Avatar Race in Violent Video Games on Racial Attitudes and Aggression. Social Psychological and Personality Science, 5(6), 698-704. https://doi.org/10.1177/1948550614528008

Yang, G. S., Huesmann, L. R., \& Bushman, B. J. (2014). Effects of playing a violent video game as male versus female avatar on subsequent aggression in male and female players. Aggressive Behavior, 40(6), 537-541. https://doi.org/10.1002/ab.21551

Zhang, J. W., Howell, R. T., \& Iyer, R. (2014). Engagement with natural beauty moderates the positive relation between connectedness with nature and psychological well-being. Journal of Environmental Psychology, 38, 55-63. https://doi.org/10.1016/j.jenvp.2013.12.013 
Table 1. A summary of the studies indicating negative or null effects (when positive effects were expected) as a result of screen use sorted by media type and domain.

\begin{tabular}{|c|c|c|c|c|c|}
\hline Media type & Domain & $\begin{array}{c}\text { Study } \\
\text { population }\end{array}$ & Year & Authors & Findings \\
\hline Mobile & Cognition & Adults & 2014 & Mun et al. & $\begin{array}{l}\text { A decrease in spatial attention abilities and in ERP } \\
\text { components related to attention }\end{array}$ \\
\hline Mobile & Cognition & Adults & 2017 & Ward et al. & $\begin{array}{l}\text { A decrease in working memory and fluid intelligence } \\
\text { performance in the presence of one's personal mobile } \\
\text { phone even when not using it }\end{array}$ \\
\hline TV & Aggression & Adults & 1990 & Bushman \& Geen & $\begin{array}{l}\text { An increase in aggressive thoughts, self-reported } \\
\text { hostility and physiological arousal after watching } \\
\text { violent TV content }\end{array}$ \\
\hline $\mathrm{TV}$ & Aggression & Adults & 1997 & Anderson & $\begin{array}{l}\text { An increase in self-reported hostility after watching } \\
\text { violent TV content }\end{array}$ \\
\hline TV & Aggression & Adults & 1998 & Bushman & $\begin{array}{l}\text { An increase in aggressive thoughts after watching } \\
\text { violent TV content }\end{array}$ \\
\hline TV & Aggression & Adults & 2009 & Scharrer & $\begin{array}{l}\text { An increase in state aggressiveness after watching } \\
\text { violent TV content }\end{array}$ \\
\hline $\mathrm{TV}$ & Aggression & $\begin{array}{l}\text { Children }(3-5 \\
\text { years) }\end{array}$ & 1971 & Steuer et al. & $\begin{array}{l}\text { An increase in aggressive play behavior and } \\
\text { interpersonal aggression after watching a violent } \mathrm{TV} \\
\text { clip }\end{array}$ \\
\hline TV & Aggression & $\begin{array}{l}\text { Children (3-5 } \\
\text { years) }\end{array}$ & 1973 & Friedrich \& Stein & $\begin{array}{l}\text { An increase in interpersonal aggression after } \\
\text { watching a violent TV clip (but also an increase in } \\
\text { pro-social behavior after watching a pro-social TV } \\
\text { clip) }\end{array}$ \\
\hline TV & Aggression & $\begin{array}{l}\text { Children }(3-6 \\
\text { years) }\end{array}$ & 1963 & Bandura et al. & $\begin{array}{l}\text { An increase in aggressive play behavior after } \\
\text { watching a violent TV clip }\end{array}$ \\
\hline $\mathrm{TV}$ & Aggression & $\begin{array}{l}\text { Children (3-6 } \\
\text { years) }\end{array}$ & 1965 & Hicks & $\begin{array}{l}\text { An increase in aggressive play behavior after } \\
\text { watching a violent } T V \text { clip }\end{array}$ \\
\hline
\end{tabular}




\begin{tabular}{|c|c|c|c|c|c|}
\hline TV & Aggression & $\begin{array}{l}\text { Children }(5-9 \\
\text { years) }\end{array}$ & 1972 & Liebert \& Baron & $\begin{array}{l}\text { An increase in aggressive play behavior and } \\
\text { interpersonal aggression after watching a violent } \mathrm{TV} \\
\text { clip }\end{array}$ \\
\hline TV & Cognition & Adults & 2002 & Bushman \& Bonacci & $\begin{array}{l}\text { A decrease in memory performance after watching a } \\
\text { sexual or a violent TV clip }\end{array}$ \\
\hline TV & $\begin{array}{l}\text { Physical } \\
\text { fitness and } \\
\text { nutrition }\end{array}$ & $\begin{array}{l}\text { Adults and } \\
\text { children }(7- \\
11 \text { years old })\end{array}$ & 2009 & Harris et al. & $\begin{array}{l}\text { Higher food consumption after watching a TV clip } \\
\text { with embedded food ads }\end{array}$ \\
\hline TV & $\begin{array}{l}\text { Physical } \\
\text { fitness and } \\
\text { nutrition }\end{array}$ & Adults & 2009 & Higgs \& Woodward & $\begin{array}{l}\text { Higher snack consumption and impaired memory for } \\
\text { lunch after eating lunch while watching TV }\end{array}$ \\
\hline TV & Stereotypes & Adults & 2000 & Milburn et al. & $\begin{array}{l}\text { An increase in stereotypical thinking after watching a } \\
\text { stereotypical TV clip }\end{array}$ \\
\hline TV & Stereotypes & Adults & 2005 & Ferguson et al. & $\begin{array}{l}\text { An increase in stereotypical thinking after watching a } \\
\text { stereotypical TV clip }\end{array}$ \\
\hline TV & Stereotypes & Adults & 2008 & Mastro et al. & $\begin{array}{l}\text { An increase in stereotypical thinking after watching a } \\
\text { stereotypical TV clip }\end{array}$ \\
\hline TV & Stereotypes & Adults & 2009 & Mastro et al. & $\begin{array}{l}\text { An increase in stereotypical thinking after watching a } \\
\text { stereotypical TV clip }\end{array}$ \\
\hline $\begin{array}{l}\text { TV and } \\
\text { videogames }\end{array}$ & Aggression & $\begin{array}{l}\text { Children }(4-6 \\
\text { years) }\end{array}$ & 1987 & Silvern \& Williamson & $\begin{array}{l}\text { An increase in aggressive play after watching violent } \\
\text { TV content or playing a violent videogame }\end{array}$ \\
\hline $\begin{array}{l}\text { TV and } \\
\text { videogames }\end{array}$ & $\begin{array}{l}\text { Aggression } \\
\text { and physical } \\
\text { fitness }\end{array}$ & $\begin{array}{l}\text { Children (3rd } \\
\text { - 4th grade) }\end{array}$ & 1999 & Robinson & $\begin{array}{l}\text { A decrease in adiposity after an intervention aimed at } \\
\text { decreasing TV and videogame use }\end{array}$ \\
\hline $\begin{array}{l}\text { TV and } \\
\text { videogames }\end{array}$ & $\begin{array}{l}\text { Aggression } \\
\text { and physical } \\
\text { fitness }\end{array}$ & $\begin{array}{l}\text { Children (3rd } \\
\text { - 4th grade) }\end{array}$ & 2001 & Robinson et al. & $\begin{array}{l}\text { A decrease in aggressive behavior after an } \\
\text { intervention aimed at decreasing TV and videogame } \\
\text { use }\end{array}$ \\
\hline
\end{tabular}




\begin{tabular}{|c|c|c|c|c|c|}
\hline Videogames & Aggression & $\begin{array}{l}\text { Adolescents } \\
(14 \text { years })\end{array}$ & 2007 & Konijn et al. & $\begin{array}{l}\text { An increase in aggressive behavior after playing a } \\
\text { violent videogame }\end{array}$ \\
\hline Videogames & Aggression & Adults & 1986 & Anderson \& Ford & $\begin{array}{l}\text { An increase in hostile feelings and feelings of anxiety } \\
\text { after playing a violent videogame }\end{array}$ \\
\hline Videogames & Aggression & Adults & 1994 & Calvert \& Tan & $\begin{array}{l}\text { An increase in aggressive cognitoins and } \\
\text { physiological arousal after playing a violent } \\
\text { videogame }\end{array}$ \\
\hline Videogames & Aggression & Adults & 1995 & Anderson \& Morrow & $\begin{array}{l}\text { An increase in aggressive behavior after playing a } \\
\text { violent videogame competitively (vs. playing it } \\
\text { cooperatively) }\end{array}$ \\
\hline Videogames & Aggression & Adults & 1996 & Ballard \& Wiest & $\begin{array}{l}\text { An increase in hostile feelings and physiological } \\
\text { arousal after playing a violent videogame }\end{array}$ \\
\hline Videogames & Aggression & Adults & 1999 & Ballard \& Lineberger & $\begin{array}{l}\text { A decrease in pro-social behavior and an increase in } \\
\text { aggressive behavior after playing a violent } \\
\text { videogame }\end{array}$ \\
\hline Videogames & Aggression & Adults & 2000 & Anderson \& Dill & $\begin{array}{l}\text { An increase in aggressive behavior, aggressive } \\
\text { cognitions and hostile feelings after playing a violent } \\
\text { videogame }\end{array}$ \\
\hline Videogames & Aggression & Adults & 2001 & Tamborini et al. & $\begin{array}{l}\text { An increase in hostile feelings after playing or } \\
\text { observing a violent videogame }\end{array}$ \\
\hline Videogames & Aggression & Adults & 2002 & Bartholow \& Anderson & $\begin{array}{l}\text { An increase in aggressive behavior after playing a } \\
\text { violent videogame }\end{array}$ \\
\hline Videogames & Aggression & Adults & 2002 & Bushman \& Anderson & $\begin{array}{l}\text { An increase in aggressive cognitions after playing a } \\
\text { violent videogame }\end{array}$ \\
\hline
\end{tabular}




\begin{tabular}{|c|c|c|c|c|c|}
\hline Videogames & Aggression & Adults & 2002 & Williams \& Clippinger & $\begin{array}{l}\text { An increase in aggressive and hostile thoughts after } \\
\text { playing a non-violent videogame against the } \\
\text { computer (vs. playing a human opponent) }\end{array}$ \\
\hline Videogames & Aggression & Adults & 2003 & Anderson \& Murphy & $\begin{array}{l}\text { An increase in aggressive behavior after playing a } \\
\text { violent videogame }\end{array}$ \\
\hline Videogames & Aggression & Adults & 2004 & Anderson et al. & $\begin{array}{l}\text { An increase in physiological arousal, aggressive } \\
\text { cognitions and aggressive behavior after playing a } \\
\text { violent videogame }\end{array}$ \\
\hline Videogames & Aggression & Adults & 2004 & Tamborini et al. & $\begin{array}{l}\text { An increase in hostile feelings after playing or } \\
\text { observing a violent videogame }\end{array}$ \\
\hline Videogames & Aggression & Adults & 2005 & Bartholow et al. & $\begin{array}{l}\text { An increase in aggressive behavior after playing a } \\
\text { violent videogame }\end{array}$ \\
\hline Videogames & Aggression & Adults & 2005 & Carnagey \& Anderson & $\begin{array}{l}\text { An increase in aggressive behavior, aggressive } \\
\text { cognitions and hostile feelings after playing a violent } \\
\text { videogame }\end{array}$ \\
\hline Videogames & Aggression & Adults & 2005 & Kirsh \& Mounts & $\begin{array}{l}\text { An increase in aggressive cognitions after playing a } \\
\text { violent videogame }\end{array}$ \\
\hline Videogames & Aggression & Adults & 2005 & Sheese \& Graziano & $\begin{array}{l}\text { An increase in anti-social behavior after playing a } \\
\text { violent videogame }\end{array}$ \\
\hline Videogames & Aggression & Adults & 2006 & Eastin & $\begin{array}{l}\text { An increase in aggressive cognitions after playing a } \\
\text { violent videogame, especially when there is a sex } \\
\text { match between the player and the avatar and when } \\
\text { playing against a human male opponent (vs. playing } \\
\text { the computer or a female opponent) }\end{array}$ \\
\hline Videogames & Aggression & Adults & 2006 & Eastin \& Griffiths & $\begin{array}{l}\text { An increase in aggressive cognitions after playing a } \\
\text { violent videogame, especially when playing in VR } \\
\text { mode }\end{array}$ \\
\hline
\end{tabular}




\begin{tabular}{|c|c|c|c|c|c|}
\hline Videogames & Aggression & Adults & 2006 & Farrar et al. & $\begin{array}{l}\text { An increase in hostile thoughts after playing a highly } \\
\text { graphical violent videogame }\end{array}$ \\
\hline Videogames & Aggression & Adults & 2007 & Barlett et al. & $\begin{array}{l}\text { An increase in physiological arousal, aggressive } \\
\text { cognitions and hostile feelings after playing a violent } \\
\text { videogame }\end{array}$ \\
\hline Videogames & Aggression & Adults & 2007 & Carnagey et al. & $\begin{array}{l}\text { A decrease in physiological arousal while watching } \\
\text { real violence after playing a violent videogame }\end{array}$ \\
\hline Videogames & Aggression & Adults & 2007 & Eastin & $\begin{array}{l}\text { An increase in hostile feelings after playing a violent } \\
\text { videogame, especially when playing in a large group }\end{array}$ \\
\hline Videogames & Aggression & Adults & 2007 & Kirsh \& Mounts & $\begin{array}{l}\text { A dectrease in the ability to recognize happy faces } \\
\text { after playing a violent videogame }\end{array}$ \\
\hline Videogames & Aggression & Adults & 2008 & Barlett et al. & $\begin{array}{l}\text { An increase in aggressive cognitions and hostile } \\
\text { feelings after playing a violent videogame }\end{array}$ \\
\hline Videogames & Aggression & Adults & 2009 & Anderson \& Carnagey & $\begin{array}{l}\text { An increase in aggressive behavior, aggressive } \\
\text { cognitions and hostile feelings after playing a violent } \\
\text { videogame }\end{array}$ \\
\hline Videogames & Aggression & Adults & 2010 & Fischer et al. & $\begin{array}{l}\text { An increase in aggressive behavior after playing a } \\
\text { violent videogame, especially with a personalized } \\
\text { avatar }\end{array}$ \\
\hline Videogames & Aggression & Adults & 2010 & Schmierbach & $\begin{array}{l}\text { An increase in aggressive cognitions after playing a } \\
\text { violent videogame competitively }\end{array}$ \\
\hline Videogames & Aggression & Adults & 2011 & Adachi \& Willoughby & $\begin{array}{l}\text { An increase in aggressive behavior after playing a } \\
\text { videogame competitively (vs. playing it } \\
\text { cooperatively) regardless of game violence level }\end{array}$ \\
\hline
\end{tabular}




\begin{tabular}{|c|c|c|c|c|c|}
\hline Videogames & Aggression & Adults & 2011 & Bushman \& Gibson & $\begin{array}{l}\text { An increase in aggressive behavior after playing a } \\
\text { violent videogame }\end{array}$ \\
\hline Videogames & Aggression & Adults & 2011 & Greitemeyer \& McLatchie & $\begin{array}{l}\text { A decrease in pro-social cognitions and an increase in } \\
\text { aggressive behavior after playing a violent video } \\
\text { game }\end{array}$ \\
\hline Videogames & Aggression & Adults & 2011 & Teng et al. & $\begin{array}{l}\text { An increase in pro-violence attitudes after playing a } \\
\text { violent videogame }\end{array}$ \\
\hline Videogames & Aggression & Adults & 2013 & Hasan et al. & $\begin{array}{l}\text { An increase in physiological stress response and in } \\
\text { aggressive behavior after playing a violent } \\
\text { videogame }\end{array}$ \\
\hline Videogames & Aggression & Adults & 2013 & Hollingdale \& Greitemeyer & $\begin{array}{l}\text { An increase in aggressive behavior after playing a } \\
\text { violent videogame, especially with a personalized } \\
\text { avatar }\end{array}$ \\
\hline Videogames & Aggression & Adults & 2014 & Greitemeyer & $\begin{array}{l}\text { An increase in aggressive behavior after playing a } \\
\text { violent videogame }\end{array}$ \\
\hline Videogames & Aggression & Adults & 2014 & Hollingdale \& Greitemeyer & $\begin{array}{l}\text { An increase in aggressive behavior after playing a } \\
\text { violent videogame, especially when playing against a } \\
\text { human opponent (vs. playing against the computer) }\end{array}$ \\
\hline Videogames & Aggression & $\begin{array}{l}\text { Children }(4 \text { th } \\
\text { - } 5 \text { th grade) }\end{array}$ & 1986 & Cooper \& Mackie & $\begin{array}{l}\text { An increase in aggressive play in girls after playing a } \\
\text { violent videogame }\end{array}$ \\
\hline Videogames & Aggression & $\begin{array}{l}\text { Children }(5-7 \\
\text { years) }\end{array}$ & 1988 & Schutte et al. & $\begin{array}{l}\text { An increase in aggressive play after playing a violent } \\
\text { videogame }\end{array}$ \\
\hline Videogames & Aggression & $\begin{array}{l}\text { Children }(7-8 \\
\text { years })\end{array}$ & 1995 & Irwin \& Gross & $\begin{array}{l}\text { An increase in aggressive play and in interpersonal } \\
\text { aggressuin after playing a violent videogame }\end{array}$ \\
\hline
\end{tabular}




\begin{tabular}{|c|c|c|c|c|c|}
\hline Videogames & Aggression & $\begin{array}{l}\text { Children }(8- \\
11 \text { years })\end{array}$ & 1998 & Kirsh & $\begin{array}{l}\text { An increase in aggressive cognitions after playing a } \\
\text { violent videogame }\end{array}$ \\
\hline Videogames & Aggression & $\begin{array}{l}\text { Children and } \\
\text { adolescents } \\
\text { (8-10 years } \\
\text { and } 12-15 \\
\text { years) }\end{array}$ & 1987 & Chambers \& Ascione & $\begin{array}{l}\text { A decrease in pro-social behavior after playing a } \\
\text { violent videogame }\end{array}$ \\
\hline Videogames & Aggression & $\begin{array}{l}\text { Children }(10- \\
13 \text { years })\end{array}$ & 2008 & Polman et al. & $\begin{array}{l}\text { An increase in aggressive behavior in boys only after } \\
\text { playing a violent videogame }\end{array}$ \\
\hline Videogames & Body image & Adults & 2008 & Barlett \& Harris & $\begin{array}{l}\text { A decrease in body esteem after playing against a } \\
\text { muscular avatar (men) or as a super-model like avatar } \\
\text { (women) }\end{array}$ \\
\hline Videogames & Cognition & Adults & 1994 & Greenfield et al. & $\begin{array}{l}\text { No increase in spatial skills after training with a } \\
\text { videogame requiring the use of these skills }\end{array}$ \\
\hline Videogames & Cognition & Adults & 2002 & Sims \& Mayer & $\begin{array}{l}\text { No increase in spatial skills after training with a } \\
\text { videogame requiring the use of these skills }\end{array}$ \\
\hline Videogames & Cognition & Adults & 2007 & Fischer et al. & $\begin{array}{l}\text { An increase in the willingness to perform risky } \\
\text { driving behavior after playing a risk-taking driving } \\
\text { game }\end{array}$ \\
\hline Videogames & Cognition & Adults & 2008 & Boot et al. & $\begin{array}{l}\text { No increase in various cognitive skills after } \\
\text { videogame training }\end{array}$ \\
\hline Videogames & Cognition & Adults & 2013 & Boot et al. & $\begin{array}{l}\text { No increase in various cognitive skills after } \\
\text { videogame training }\end{array}$ \\
\hline Videogames & Cognition & Adults & 2014 & van Ravenzwaaij et al. & $\begin{array}{l}\text { No increase in processing speed after videogame } \\
\text { training }\end{array}$ \\
\hline
\end{tabular}




\begin{tabular}{|c|c|c|c|c|c|}
\hline Videogames & Cognition & $\begin{array}{l}\text { Children (6-9 } \\
\text { years) }\end{array}$ & 2010 & Weis \& Cerankosky & $\begin{array}{l}\text { A decrease in academic activity and lower academic } \\
\text { achievements } 4 \text { months after receiving a videogame } \\
\text { console }\end{array}$ \\
\hline Videogames & Mood & $\begin{array}{l}\text { Adults, } \\
\text { children and } \\
\text { adolescents } \\
(9-15 \text { years }) \\
\end{array}$ & 1985 & Nelson \& Carlson & $\begin{array}{l}\text { An increase in depression, hostility, aggression and } \\
\text { fatigue and a decrease in concentration, vigor and } \\
\text { social affection after a prolonged videogame play } \\
\text { period }\end{array}$ \\
\hline Videogames & $\begin{array}{l}\text { Physical } \\
\text { fitness and } \\
\text { nutrition }\end{array}$ & Adults & 2011 & Oldham-Cooper et al. & $\begin{array}{l}\text { Less satiety and a decrease in memory for food items } \\
\text { consumed after eating while playing a videogame }\end{array}$ \\
\hline Videogames & $\begin{array}{l}\text { Physical } \\
\text { fitness and } \\
\text { nutrition }\end{array}$ & $\begin{array}{l}\text { Children }(8- \\
10 \text { years })\end{array}$ & 2010 & Graves et al. & $\begin{array}{l}\text { No increase in physical activity or phisical fitness } \\
\text { after training with active videogames }\end{array}$ \\
\hline Videogames & $\begin{array}{l}\text { Physical } \\
\text { fitness and } \\
\text { nutrition }\end{array}$ & $\begin{array}{l}\text { Children }(9- \\
12 \text { years) }\end{array}$ & 2012 & Baranowski et al. & $\begin{array}{l}\text { No increase in physical activity or phisical fitness } \\
\text { after training with active videogames }\end{array}$ \\
\hline Videogames & Stereotypes & Adults & 2009 & Behm-Morawitz \& Mastro & $\begin{array}{l}\text { A decrease in self efficacy and less favorable } \\
\text { attitudes towards women's physical abilities in } \\
\text { women and less favorable attitudes towards women's } \\
\text { cognitive abilities in women and men after playing a } \\
\text { sexualized game. }\end{array}$ \\
\hline Videogames & Stereotypes & Adults & 2014 & Yang et al. & $\begin{array}{l}\text { An increase in negative attitudes towards African - } \\
\text { Americans and in aggressive behavior after playing a } \\
\text { violent game with an African - American avatar }\end{array}$ \\
\hline Videogames & Stereotypes & Adults & 2014 & Yang et al. & $\begin{array}{l}\text { An increase in aggressive behavior after playing a } \\
\text { violent videogame as a male avatar }\end{array}$ \\
\hline $\begin{array}{l}\text { Virtual } \\
\text { reality }\end{array}$ & Aggression & Adults & 2009 & Peña et al. & $\begin{array}{l}\text { An increase in aggressive intentions and attitudes } \\
\text { after posing as a negative avatar }\end{array}$ \\
\hline
\end{tabular}


Table 2. A summary of the studies indicating positive or null effects (when negative effects were expected) as a result of screen use sorted by media type and domain.

\begin{tabular}{|c|c|c|c|c|c|}
\hline Media type & Domain & $\begin{array}{c}\text { Study } \\
\text { population }\end{array}$ & Year & Authors & Findings \\
\hline Television & Aggression & $\begin{array}{l}\text { Children }(7-11 \\
\text { years old })\end{array}$ & 1968 & Walters \& Willows & $\begin{array}{l}\text { No increase in aggressive play behavior after } \\
\text { watching a violent TV clip }\end{array}$ \\
\hline Television & $\begin{array}{l}\text { Physical fitness } \\
\text { and nutrition }\end{array}$ & Adults & 2009 & Martin et al. & No effect of TV watching on caloric intake. \\
\hline Television & Mood & $\begin{array}{l}\text { Children }(2-10 \\
\text { years old })\end{array}$ & 2012 & Mifflin et al. & $\begin{array}{l}\text { TV clips are more efficient in reducing pre- } \\
\text { operative anxiety than standard methods such as } \\
\text { humor or talk }\end{array}$ \\
\hline Television & Mood & $\begin{array}{l}\text { Children (4-9 } \\
\text { years old) }\end{array}$ & 2013 & Kerimoglu et al. & $\begin{array}{l}\text { TV clips are as efficient in reducing pre-operative } \\
\text { anxiety as anti-anxiety medication }\end{array}$ \\
\hline Television & Mood & $\begin{array}{l}\text { Children }(2-7 \\
\text { years old })\end{array}$ & 2015 & Kim et al. & $\begin{array}{l}\text { TV clips are as efficient in reducing pre-operative } \\
\text { anxiety as parental presence }\end{array}$ \\
\hline Videogames & Aggression & $\begin{array}{l}\text { Adolescents } \\
\text { (8th grade) }\end{array}$ & 1987 & Winkel et al. & $\begin{array}{l}\text { No effect of violent videogames on aggressive } \\
\text { behavior }\end{array}$ \\
\hline Videogames & Aggression & Adults & 1995 & Scott & $\begin{array}{l}\text { No effect of violent videogames on self-reported } \\
\text { aggression }\end{array}$ \\
\hline Videogames & Aggression & Adults & 2005 & Williams \& Skoric & $\begin{array}{l}\text { No effect of violent videogames on self-reported } \\
\text { aggression }\end{array}$ \\
\hline Videogames & Aggression & Adults & 2008 & Ferguson et al. & $\begin{array}{l}\text { No effect of violent videogames on aggressive } \\
\text { behavior }\end{array}$ \\
\hline Videogames & Aggression & $\begin{array}{l}\text { Children (2nd - } \\
\text { 6th grade) }\end{array}$ & 1987 & Graybill et al. & $\begin{array}{l}\text { No effect of violent videogames on aggressive } \\
\text { behavior }\end{array}$ \\
\hline Videogames & Aggression & $\begin{array}{l}\text { Children }(8-12 \\
\text { years })\end{array}$ & 2001 & Fleming \& Rick Wood & $\begin{array}{l}\text { No effect of violent videogames on physiological } \\
\text { arousal and self-reported arousal, aggression, affect } \\
\text { and mood }\end{array}$ \\
\hline Videogames & Cognition & Adults & 1985 & Gagnon & Improvement in spatial abilities \\
\hline
\end{tabular}




\begin{tabular}{|c|c|c|c|c|c|}
\hline Videogames & Cognition & Adults & 1986 & Dorval \& Pepin & Improvement in spatial abilities \\
\hline Videogames & Cognition & Adults & 1989 & Orosy-Fildes \& Allan & Improvement in spatial abilities \\
\hline Videogames & Cognition & Adults & 1994 & Greenfield et al. & Improvement in executive functions \\
\hline Videogames & Cognition & Adults & 1994 & Greenfield et al. & Improvement in spatial abilities \\
\hline Videogames & Cognition & Adults & 1994 & Okagaki \& Frensch & Improvement in spatial abilities \\
\hline Videogames & Cognition & Adults & 2003 & Green \& Bavelier & Improvement in spatial abilities \\
\hline Videogames & Cognition & Adults & 2006 & Green \& Bavelier & Improvement in spatial abilities \\
\hline Videogames & Cognition & Adults & 2006 & Green \& Bavelier & Improvement in spatial abilities \\
\hline Videogames & Cognition & Adults & 2007 & Feng et al. & Improvement in spatial abilities \\
\hline Videogames & Cognition & Adults & 2007 & Green \& Bavelier & Improvement in spatial abilities \\
\hline Videogames & Cognition & Adults & 2009 & Barlett et al. & Improvement in executive functions \\
\hline Videogames & Cognition & Adults & 2009 & Li et al. & Improvement in spatial abilities \\
\hline Videogames & Cognition & Adults & 2010 & Green at al. & Improvement in executive functions \\
\hline Videogames & Cognition & Adults & 2010 & Li et al. & Improvement in spatial abilities \\
\hline Videogames & Cognition & Adults & 2012 & Green et al. & Improvement in executive functions \\
\hline Videogames & Cognition & Adults & 2012 & Sanchez & Improvement in spatial abilities \\
\hline Videogames & Cognition & Adults & 2013 & Chiappe et al. & Improvement in executive functions \\
\hline Videogames & Cognition & Adults & 2013 & Choi \& Lane & Improvement in spatial abilities \\
\hline Videogames & Cognition & Adults & 2013 & Wu \& Spence & Improvement in spatial abilities \\
\hline Videogames & Cognition & Adults & 2014 & Bejjanki et al. & Improvement in spatial abilities \\
\hline Videogames & Cognition & Adults & 2015 & Buelow et al. & Improvement in executive functions \\
\hline Videogames & Cognition & Adults & 2016 & Li et al. & Improvement in spatial abilities \\
\hline Videogames & Cognition & $\begin{array}{l}\text { Adults and } \\
\text { adolescents (13 } \\
\text { years) }\end{array}$ & 1986 & Pepin \& Dorval & Improvement in spatial abilities only in the adults \\
\hline Videogames & Cognition & $\begin{array}{l}\text { Children (11 } \\
\text { years) }\end{array}$ & 1994 & $\begin{array}{l}\text { Subrahmanyam \& } \\
\text { Greenfield }\end{array}$ & Improvement in spatial abilities \\
\hline Videogames & Cognition & $\begin{array}{l}\text { Children ( } 8-9 \\
\text { years) }\end{array}$ & 2002 & De Lisi \& Wolford & Improvement in spatial abilities \\
\hline
\end{tabular}




\begin{tabular}{|c|c|c|c|c|c|}
\hline Videogames & Cognition & $\begin{array}{l}\text { Children and } \\
\text { adolescents } \\
\text { (5th }-9 \text { th } \\
\text { grade) }\end{array}$ & 1987 & McClurg \& Chaille & Improvement in spatial abilities \\
\hline Videogames & Cognition & $\begin{array}{l}\text { Elderly } \\
\text { population }\end{array}$ & 1987 & Clark et al. & Improvement in executive functions \\
\hline Videogames & Cognition & $\begin{array}{l}\text { Elderly } \\
\text { population }\end{array}$ & 1992 & Dustman et al. & Improvement in reaction times \\
\hline Videogames & Cognition & $\begin{array}{l}\text { Elderly } \\
\text { population }\end{array}$ & 1997 & Goldstein et al. & Improvement in reaction times and well-being \\
\hline Videogames & Cognition & $\begin{array}{l}\text { Elderly } \\
\text { population }\end{array}$ & 2008 & Basak et al. & $\begin{array}{l}\text { Improvement in executive functions and spatial } \\
\text { abilities }\end{array}$ \\
\hline Videogames & Cognition & $\begin{array}{l}\text { Elderly } \\
\text { population }\end{array}$ & 2011 & Stern et al. & Improvement in executive functions \\
\hline Videogames & Cognition & $\begin{array}{l}\text { Elderly } \\
\text { population }\end{array}$ & 2012 & Anderson-Hanley et al. & Improvement in executive functions \\
\hline Videogames & Cognition & $\begin{array}{l}\text { Elderly } \\
\text { population }\end{array}$ & 2013 & Belchior et al. & Improvement in spatial abilities \\
\hline Videogames & $\begin{array}{l}\text { Cognition and } \\
\text { physical fitness }\end{array}$ & $\begin{array}{l}\text { Elderly } \\
\text { population }\end{array}$ & 2012 & Maillot et al. & $\begin{array}{l}\text { Improvement in executive functions and physical } \\
\text { fitness }\end{array}$ \\
\hline Videogames & Mood & Adults & 2012 & Valadez \& Ferguson & No effect of violent videogames on mood \\
\hline Videogames & Mood & $\begin{array}{l}\text { Children (4-12 } \\
\text { years) }\end{array}$ & 2006 & Patel et al. & Reduction in anxiety prior to surgery \\
\hline Videogames & $\begin{array}{l}\text { Mood and } \\
\text { aggression }\end{array}$ & Adults & 2010 & Ferguson \& Rueda & $\begin{array}{l}\text { No effect of violent videogames on mood or } \\
\text { aggressive behavior }\end{array}$ \\
\hline Videogames & Neural changes & $\begin{array}{l}\text { Adolescents } \\
\text { (13 years old) }\end{array}$ & 2009 & Haier et al. & Changes in gray matter \\
\hline Videogames & Neural changes & Adults & 2012 & Colom et al. & Changes in gray matter \\
\hline Videogames & Neural changes & Adults & 2012 & Lee et al. & $\begin{array}{l}\text { Changes in activity of brain areas related to visuo- } \\
\text { spatial attention and goal-directed movement after } \\
\text { videogame training }\end{array}$ \\
\hline
\end{tabular}




\begin{tabular}{|c|c|c|c|c|c|}
\hline Videogames & Neural changes & Adults & 2012 & Voss et al. & $\begin{array}{l}\text { Changes in activity of specific brain networks } \\
\text { according to the specific training strategy used }\end{array}$ \\
\hline Videogames & Neural changes & Adults & 2012 & Wu et al. & Changes in an attention-related ERP component \\
\hline Videogames & Neural changes & Adults & 2013 & Martinez et al. & $\begin{array}{l}\text { Changes in resting-state functional connectivity in } \\
\text { networks involved with various cognitive functions } \\
\text { after videogame training }\end{array}$ \\
\hline Videogames & Neural changes & Adults & 2014 & Kuhn et al. & Changes in gray matter \\
\hline Videogames & Neural changes & Adults & 2014 & Nikolaidis et al. & $\begin{array}{l}\text { Changes in the activity of brain networks after } \\
\text { training which predicted improvement in a working } \\
\text { memory task }\end{array}$ \\
\hline Videogames & Neural changes & Adults & 2017 & Gleich et al. & $\begin{array}{l}\text { Changes in the activity of the pre-frontal cortex and } \\
\text { the hippocampus related to reward processing and } \\
\text { correlated with game performance }\end{array}$ \\
\hline Videogames & Physical fitness & $\begin{array}{l}\text { Children } \\
\text { (elementary } \\
\text { school) }\end{array}$ & 2012 & Gao \& Podlog & An increase in physical activity \\
\hline Videogames & $\begin{array}{l}\text { Physical fitness } \\
\text { and nutrition }\end{array}$ & Adults & 2012 & Lyons et al. & An increase in physical activity \\
\hline Videogames & $\begin{array}{l}\text { Prosocial } \\
\text { behavior }\end{array}$ & Adults & 2009 & Gentile & $\begin{array}{l}\text { An increase in prosocial behavior after playing a } \\
\text { prosocial game (but also a decrease in prosocial } \\
\text { behavior after playing a violent game) }\end{array}$ \\
\hline Videogames & $\begin{array}{l}\text { Prosocial } \\
\text { behavior }\end{array}$ & Adults & 2009 & $\begin{array}{l}\text { Greitemeyer \& } \\
\text { Osswald }\end{array}$ & $\begin{array}{l}\text { An increase in prosocial thoughts and a decrease in } \\
\text { aggressive thoughts after playing a prosocial } \\
\text { videogame }\end{array}$ \\
\hline Videogames & $\begin{array}{l}\text { Prosocial } \\
\text { behavior }\end{array}$ & Adults & 2010 & $\begin{array}{l}\text { Greitemeyer \& } \\
\text { Osswald }\end{array}$ & $\begin{array}{l}\text { An increase in prosocial behavior after playing a } \\
\text { prosocial game }\end{array}$ \\
\hline Videogames & $\begin{array}{l}\text { Prosocial } \\
\text { behavior }\end{array}$ & Adults & 2010 & Greitemeyer et al. & $\begin{array}{l}\text { An increase in empathy and a decrease in } \\
\text { schadenfreude after playing a prosocial game }\end{array}$ \\
\hline Videogames & $\begin{array}{l}\text { Prosocial } \\
\text { behavior }\end{array}$ & Adults & 2011 & $\begin{array}{l}\text { Greitemeyer \& } \\
\text { Osswald }\end{array}$ & $\begin{array}{l}\text { An increase in prosocial thoughts and a decrease in } \\
\text { aggressive thoughts after playing a prosocial } \\
\text { videogame }\end{array}$ \\
\hline
\end{tabular}




\begin{tabular}{|l|l|l|l|l|l|}
\hline Videogames & $\begin{array}{l}\text { Prosocial } \\
\text { behavior }\end{array}$ & Adults & 2012 & Ewoldsen et al. & $\begin{array}{l}\text { An increase in prosocial behavior after playing a } \\
\text { violent videogame cooperatively }\end{array}$ \\
\hline Videogames & $\begin{array}{l}\text { Prosocial } \\
\text { behavior }\end{array}$ & Adults & 2012 & Greitemeyer et al. & $\begin{array}{l}\text { A decrease in aggressive behavior, cognition and } \\
\text { affect after playing a prosocial videogame }\end{array}$ \\
\hline Videogames & $\begin{array}{l}\text { Prosocial } \\
\text { behavior }\end{array}$ & Adults & 2013 & Greitemeyer & $\begin{array}{l}\text { An increase in cooperative thoughts after playing a } \\
\text { violent videogame cooperatively (but also a } \\
\text { decrease in empathy after playing the game solo) }\end{array}$ \\
\hline Videogames & $\begin{array}{l}\text { Prosocial } \\
\text { behavior }\end{array}$ & Adults & 2013 & Tear \& Nielsen & $\begin{array}{l}\text { No decrease in prosocial behavior after playing } \\
\text { antisocial or violent videogames }\end{array}$ \\
\hline Videogames & $\begin{array}{l}\text { Prosocial } \\
\text { behavior }\end{array}$ & Adults & 2014 & Velez et al. & $\begin{array}{l}\text { A decrease in aggressive cognitions after playing a } \\
\text { violent videogame cooperatively }\end{array}$ \\
\hline
\end{tabular}




\section{Supplementary material}

\section{Search term used to search the Pubmed database}

We searched the Pubmed database with the following search query: ((((Television[Title] OR TV[Title] OR mobile[Title] OR phone[Title] OR tablet[Title] OR gaming[Title] OR videogame[Title] OR "videogames"[Title] OR "videogame"[Title] OR computer[Title] OR internet[Title]))) AND (empathy[Title] OR sociability[Title] OR aggression[Title] OR language[Title] OR literacy[Title] OR memory[Title] OR emotion[Title] OR "emotional regulation"[Title] OR obesity[Title] OR depression[Title] OR psychological[Title] OR psychosocial[Title] OR physical[Title] OR emotional[Title] OR behavior[Title] OR "physical activity"[Title] OR academic[Title] OR achievement[Title] OR visual[Title] OR auditory[Title] OR cognitive[Title] OR cognition[Title] OR sensory[Title] OR stress[Title] OR sleep[Title] OR interpersonal[Title] OR "interpersonal interaction"[Title] OR prosocial[Title] OR antisocial[Title] OR well-being[Title] OR "wellbeing"[Title] OR happiness[Title] OR attention[Title] OR anxiety[Title] OR violence[Title] OR fertility[Title])) NOT (therapy[Title] OR clinical[Title] OR 3G[Title] OR EMF[Title] OR "electromagnetic field"[Title] OR "electromagnetic fields"[Title] OR diabetes[Title] OR intervention[Title] OR interventions[Title] OR surgery[Title] OR neurosurgery[Title] OR assessment[Title] OR treatment[Title] OR treatments[Title] OR therapeutic[Title] OR therapy[Title] OR application[Title] OR applications[Title] OR app[Title] OR program[Title] OR medicine[Title] OR medical[Title] OR patients[Title] OR residents[Title] OR nurses[Title] OR platform[Title] OR management[Title] OR treat[Title] OR "internetbased"[Title] OR "computer-tailored"[Title] OR "computer-based"[Title] OR "computerdelivered"[Title] OR "self-help"[Title]). In addition, we used the Pubmed advanced search option with "publication type" set to "randomized controlled trial" or "clinical trial". 